Chapman University

Chapman University Digital Commons

Computational and Data Sciences (Ph.D.)

Dissertations

Fall 12-20-2019

\title{
Contributions to Variable Selection in Complexly Sampled Case- control Models, Epidemiology of 72-hour Emergency Department Readmission, and Out-of-site Migration Rate Estimation Using Pseudo-tagged Longitudinal Data
}

Kyle Anderson

Chapman University, ander211@mail.chapman.edu

Follow this and additional works at: https://digitalcommons.chapman.edu/cads_dissertations

\section{Recommended Citation}

K. Anderson, "Contributions to variable selection in complexly sampled case- control models, epidemiology of 72-hour Emergency Department readmission, and out-of-site migration rate estimation using pseudo- tagged longitudinal data," Ph.D. dissertation, Chapman University, Orange, CA, 2019. https://doi.org/10.36837/chapman.000120

This Dissertation is brought to you for free and open access by the Dissertations and Theses at Chapman University Digital Commons. It has been accepted for inclusion in Computational and Data Sciences (Ph.D.) Dissertations by an authorized administrator of Chapman University Digital Commons. For more information, please contact laughtin@chapman.edu. 
Contributions to variable selection in complexly sampled casecontrol models, epidemiology of 72-hour Emergency Department readmission, and out-of-site migration rate estimation using pseudotagged longitudinal data

A Dissertation by Kyle Anderson

Chapman University

Orange, California

Schmid College of Science and Technology

Submitted in partial fulfilment of the requirements for the degree of Doctor of Philosophy in Computational and Data Sciences

December 2019

Committee in charge:

Cyril Rakovski, Ph.D., Committee Chair

Lisa Sparks, Ph.D.

William G. Wright, Ph.D.

Louis Ehwerhemuepha, Ph.D. 
The dissertation of Kyle Anderson is approved.

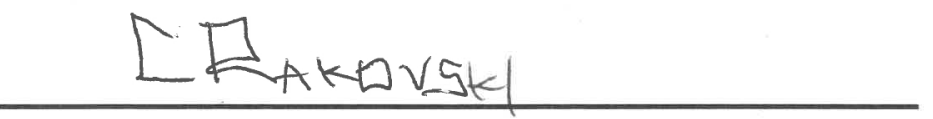

Cyril Rakovski, Ph.D., Committee Chair

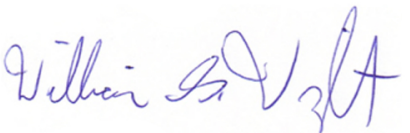

William G. Wright, Ph.D.

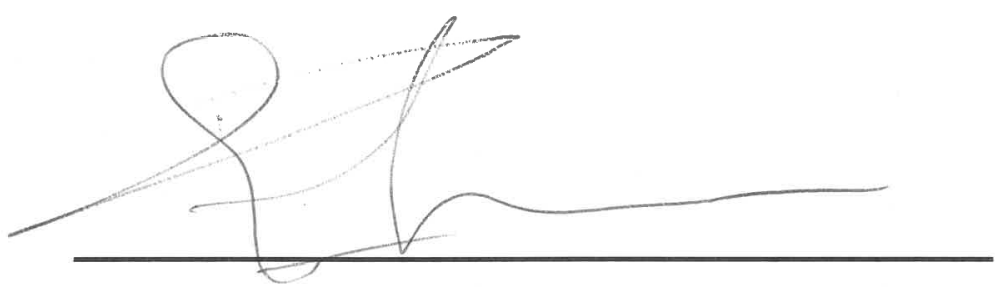

Louis'Ehwerhemuepha, Ph.D.

December 2019 
Contributions to variable selection in complexly sampled casecontrol models, epidemiology of 72-hour Emergency Department readmission, and out-of-site migration rate estimation using pseudotagged longitudinal data

Copyright (C) 2019

by Kyle Anderson 


\section{ACKNOWLEDGEMENTS}

I would like to thank Alexander Barrett, Sidy Danioko, Ehsan Yaghmaei, Jianwei Zheng, and everyone who offered thoughts and advice that were useful in completing this research. 


\section{DEDICATION}

To my friends, family, and loved ones. Thank you Mom. 


\begin{abstract}
Contributions to variable selection in complexly sampled casecontrol models, epidemiology of 72-hour Emergency Department readmission, and out-of-site migration rate estimation using pseudotagged longitudinal data

by Kyle Anderson
\end{abstract}

This work consists of three different projects.

In the first project, I analyze complexly sampled survey data, representative of the US population, to determine what lifestyle behaviors and notions held by participants are most significant with having had a cancer diagnosis. A logistic regression model was built using automatic variable selection with forward selection with backwards elimination. Our results show that sunscreen usage, level of agreeing with the statement "behaviors can affect high blood pressure", age, intent to eat more or less fruit, average daily hours spent watching tv or playing video games, and level of agreeing with the statement "I would rather not know my chances of getting cancer" were significant variables associated with a having had a cancer diagnosis.

In the second project, I developed a novel method for tracking untagged organisms over a 20 -year period, data collected at 6-month intervals. Our results showed that the staying rates, emigration/mortality rates, and immigration rates were approximately $50 \%$. We also found that $44.1 \%$ of the limpets emigrate/die within their first 6-month time interval. 
In the third project, I investigated the most significant predictors of a return to the Emergency Department within 72 hours, with a focus on adult patients with a respiratory condition. High return rates are a burden to both the Emergency Department and patients. We used a dataset extracted from a database containing billions of patient visits and implemented a nested mixed effects model to determine the most significant predictors. There were 20 risk factors found, including demographic variables, diagnostic conditions, and respiratory conditions. 


\section{TABLE OF CONTENTS}

1. Variable selection in complexly sampled survey data ....................................... 1

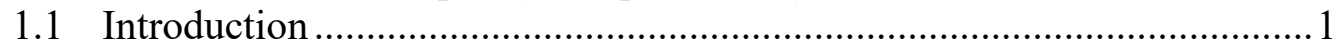

1.2 Health Informatics National Trends Survey 4....................................... 4

1.3 Automatic Variable Selection and Statistical Analysis........................... 9

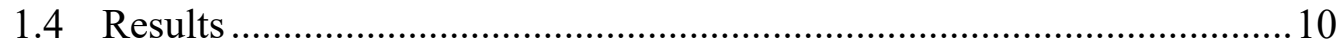

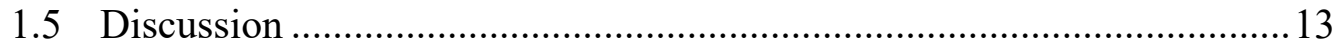

2. Out-of-site migration rate estimation using pseudo-tagged longitudinal data.. 16

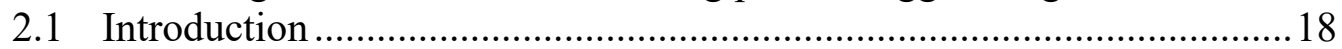

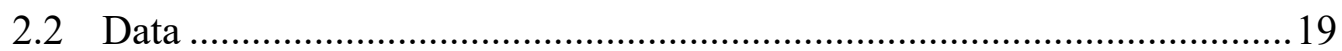

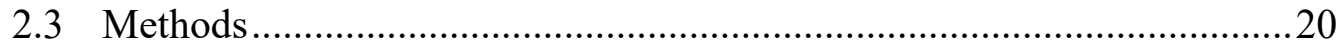

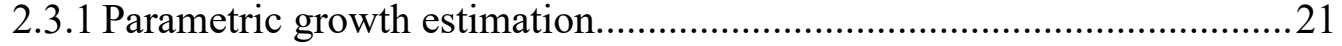

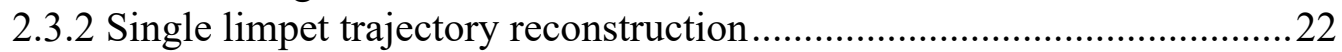

2.3.3 Number of possible limpet trajectories over two successive time points 23

2.3.4 Stepwise procedure for all trajectory reconstruction ............................23

2.3.5 Emigration/mortality, immigration, and year-to-year staying rates and

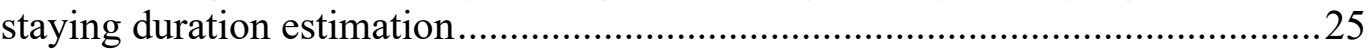

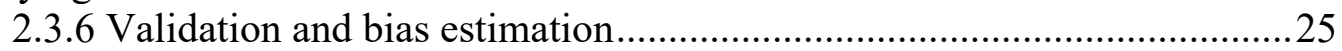

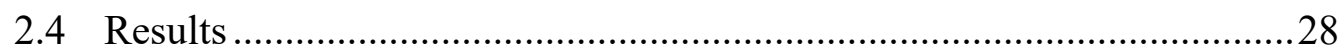

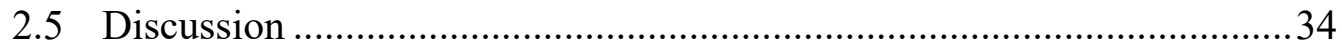

3. Epidemiology of 72-hour Emergency Department readmission ......................35

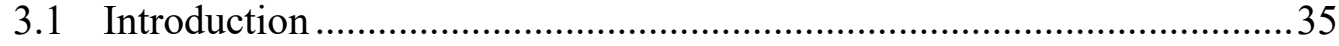

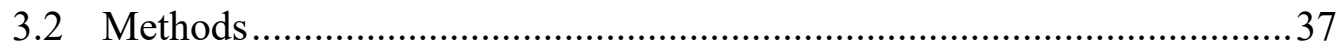

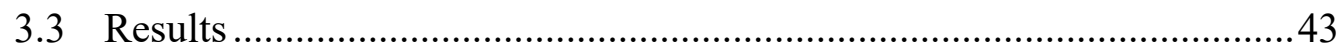

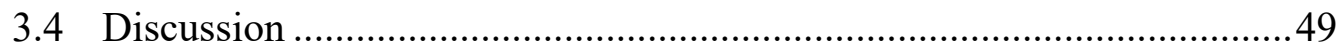

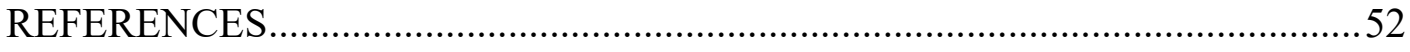

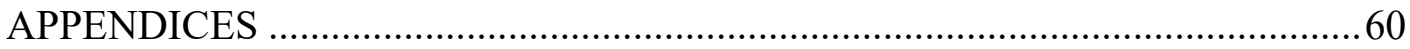




\section{LIST OF TABLES}

Table 1-1. General background characteristics of the survey responders (unweighted

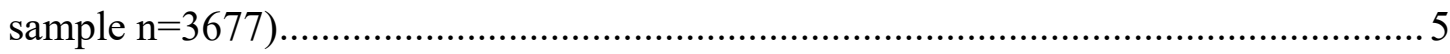

Table 1-2. Health related background characteristics of the survey responders

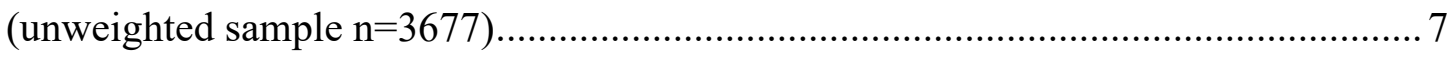

Table 1-3. Summary results from the best explanatory logistic regression model. . 11

Table 2-1. Summary statistics for the length of limpets. ..................................20

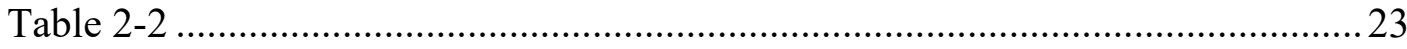

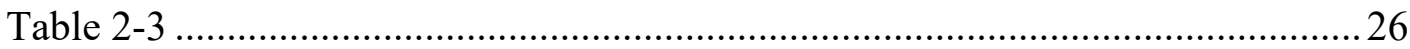

Table 2-4. Distribution of at-site staying durations. ......................................... 31

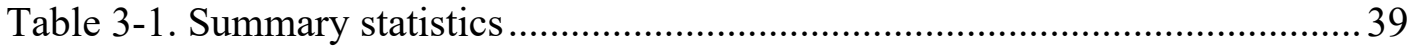

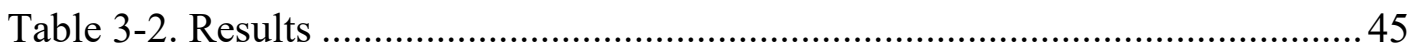

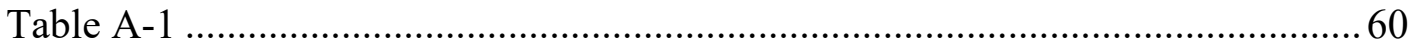




\section{LIST OF FIGURES}

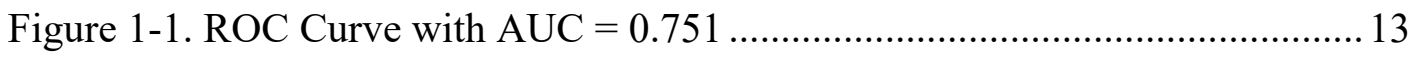

Figure 2-1. Initial shell length vs. growth after 6 months .....................................21

Figure 2-2. Estimated proportions of limpets that stayed and immigrated over time

Figure 2-3. Forecasted staying and immigration proportions ...................................30

Figure 2-4. Estimated limpet growth trajectories over all 20 years.........................32

Figure 2-5. Following a sample of limpets until all are out of the data...................33

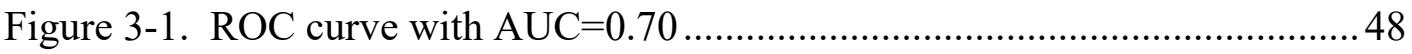




\section{Variable selection in complexly sampled survey data}

We undertake a study to determine and assess the effects of the statistically significant predictors of the behaviors and "notions" that are associated with a cancer diagnosis using the 2014 Health Information National Trends Survey data. We implemented a new and extensive logistic regression modeling using stepwise variable selection and jackknife parameter estimation that identified the best explanatory model. Our results show that age, average time spent watching TV or playing games, usage of sunscreen, fruit intake intent, and the opinion-based variables for behaviors affecting high blood pressure, as well as the participant preference of not knowing the chance of getting cancer are the optimal set of covariates impacting the chance of getting cancer. Moreover, using more sunscreen, and a higher age were associated with increases in the chances of getting cancer. Interestingly, many usually important background covariates such as race, income, gender, geographical location and others were not significant predictors of the outcome variable of interest. The conclusions of our analysis reveal new insights in the complexity of the behaviors and "attitudes" associated with a higher chance of a cancer diagnosis and will undoubtedly have important implications on the design and success of future health care messages and campaigns.

\subsection{Introduction}

A cancer diagnosis is arguably one of the most dreaded diagnoses of our time. An individual diagnosed with cancer may feel as if he or she is always with cancer, that every conversation, thought, or action is altered by this new state of being as a cancer [1-4]. Patients often report feeling their health care providers tend to speak in ways that are often difficult to understand, full of medical terms, with talk full of acronyms for chemotherapy combinations and odd treatments. The 
patient and family members often find their way through the maze of sorting through what cancer staging and tumor marker levels mean for decisions about treatment and for their day-to-day lives. They may struggle to disentangle risks, benefits, and side effects of different treatments and figure out which pros and cons are most important to their decisions about the next steps and their own lives as well as which benefits and risks the oncologist emphasizes. Often, the patient or family member may not know how to put fears and confusions into words and may not know what kinds of questions will get the answers that are most needed [4]. Research consistently reveals that a deeper knowledge of communication processes helps a person negotiate this difficult time, and often offers ways to exert some control in an overwhelming situation, and leads to better health outcomes for the individual[1-4]. Scholars in health communication recognize that information about type and stage of cancer and treatment options is like a list of ingredients in a recipe for a meal they've never had before. The ingredients are necessary to have, of course, but without instructions for what to do with them, the patient and caregivers may still feel lost as to how to move from one step to the next. As Sparks and Leahy (2018) [4] explain, communication serves a crucial role in helping an individual put the informational ingredients together while deciding whether to stir or to blend, as well as which substitutions can be made without messing up the result, what temperature works best, and how to tell when enough is enough. Many patients, providers, and caregivers may not realize they can improve healthcare communication among each other and may not realize how much that improvement can matter to a patient's sense of wellbeing and one's healthcare outcomes. Many involved in these difficult and complicated decisions have not given much thought to the confusing world of cancer and related decision-making until they are presented with the disease in some way.

Communication scholars and researchers are becoming increasingly interested in the health 
information seeking and various behavioral patterns of cancer patients [5-9]. Cancer information seeking is of particular interest because of the pervasiveness of the disease, the alarming number of types, the duration of the illness, and the enormous variety of treatment options available. Furthermore, "the process through which a patient actively learns about his or her disease and treatment, plays a pivotal role in how individuals successfully manage their own health care" [10]. Cancer patients need to become informed on the many issues related to their disease in order to make informed decisions about their choice of doctor, treatment plan, and after care.

Research on health information seeking shows that patients often desire more information about their illness, treatment options, and side effects of treatments, and that they often want more healthcare information and research literature, to supplement the information provided during the office consultation $[8,11]$.

Educating patients or possible cancer patients is the best way to ensure informed decisions and begin patient involvement in healthier practices that can have a protective or restorative effect on their health. Starting the education process and support outreach as early as possible will give the best chances to the patients to begin a healthier, more informed lifestyle [12]. It is shown that cancer patients will increase their fruit and vegetable intake [13]. This is due to either trying to gain the protective benefits regarding cancer from eating more fruit and vegetables, or to reduce the risk of secondary conditions, including such conditions as heart disease or higher blood pressure. These results also indicated that many patients showed that, in addition to engagement with their healthcare provider, that they were searching for information from non-medical sources. It can be assumed that they were searching for information to increase their chances of survival and to lower risk of cancer diagnoses. 


\subsection{Health Informatics National Trends Survey 4}

HINTS was developed by the Health Communication and Informatics Research Branch (HCIRB) of the Division of Cancer Control and Population Sciences (DCCPS) at the National Cancer Institute. HINTS uses a nationally representative sample to investigate how the American public uses and searches for cancer information. The collection process of the HINTS IV data set was started and completed in 2014 [14]. There are nearly 270 items that were asked of the participants in the 2014 HINTS, all of which were included in the analysis as possible predictors.

Analyzing the 3,677 weighted responses regarding their racial background illustrated that $60.8 \%$ considered themselves as Non-Hispanic White, $10.3 \%$ reported their race/ethnicity as NonHispanic Black, 13.8\% consider themselves to be Hispanic and 4.4\% Non-Hispanic Asian while $1.9 \%$ provided a non- illuminating answer. Roughly $51 \%$ of the respondents were designated as female. The responses regarding census region (Region) disclose that Northeast, Midwest, South, and West regions were represented in the data by $18.2,21.5,37.1$, and $23.1 \%$ of the participants respectively. The average age of participants in the study was 45.7 years with standard deviation of 16.9 years; the age group with the highest frequency was 18-34 years of age accounting for $29.6 \%$ of the population followed by $35-49$ and $50-65$ age groups accounting for 25.7 and $24.2 \%$ of the population respectively. The most common response in marital status (HD06 Marital Status) was "Married", making up 51.8\%, followed by "Single", "Divorced", and "Widowed" with 27.7, 7.4, and 5.5\% respectively. The educational background (HD07 Education) variable revealed that $14.3 \%$ attained a post-graduate degree, $24.6 \%$ of the responders earned an undergraduate college degree, $21.9 \%$ attended college but failed to obtain a degree, $17.6 \%$ completed high school, and $11.3 \%$ did not complete high school. Moving on, the income response of the survey participants shows that $7.3 \%$ make less than $\$ 10,000,24.8 \%$ earn between $\$ 20,000$ and $\$ 50,000,28.1 \%$ make 
between $\$ 50,000$ and $\$ 100,000,14.4 \%$ earn between $\$ 100,000$ and $\$ 200,000$, and $5.3 \%$ make over $\$ 200,000$ per year. Additional details for the distributions of these general background variables are shown in Table 1-1. Note that some respondents either failed to respond, or responded in error, but these options are not shown in the tables below, it is for this reason that some categories do not equal $100 \%$

Table 1-1. General background characteristics of the survey responders (unweighted sample $n=3677$ )

\begin{tabular}{|c|c|}
\hline Survey Item* & n (\%) $)^{* *}$ \\
\hline \multicolumn{2}{|l|}{ 1) Age in years ( $n=3495)$} \\
\hline $18-34$ & $70(29.6)$ \\
\hline $35-49$ & $61(25.7)$ \\
\hline $50-64$ & $57(24.2)$ \\
\hline $65-74$ & $22(9.2)$ \\
\hline $75+$ & $18(7.6)$ \\
\hline \multicolumn{2}{|l|}{ 2) Gender $(n=3608)$} \\
\hline Male & $113(47.5)$ \\
\hline Female & $121(50.9)$ \\
\hline \multicolumn{2}{|l|}{ 3) Region ( $\mathrm{n}=3677$ ) } \\
\hline Northeast & $43(18.2)$ \\
\hline Midwest & $51(21.5)$ \\
\hline South & $88(37.1)$ \\
\hline West & $55(23.1)$ \\
\hline \multicolumn{2}{|l|}{ 4) Ethnicity (n=3273) } \\
\hline Non-Hispanic White & $144(60.8)$ \\
\hline Non-Hispanic Black & $25(10.3)$ \\
\hline Hispanic & $33(13.8)$ \\
\hline Non-Hispanic Asian & $10(4.4)$ \\
\hline Non-Hispanic multiple races & $5(1.9)$ \\
\hline \multicolumn{2}{|l|}{ 5) Highest Education $(n=3526)$} \\
\hline Less than 8 years & $8(3.3)$ \\
\hline Between 8 and 11 years & $19(8)$ \\
\hline High school & $42(17.6)$ \\
\hline Post high school training & $17(7.2)$ \\
\hline Some college & $52(21.9)$ \\
\hline College graduate & $58(24.6)$ \\
\hline Postgraduate & 34 (14.3) \\
\hline 6) Marital Status $(n=3506)$ & \\
\hline
\end{tabular}




\begin{tabular}{|l|c|}
\hline Married & $123(51.8)$ \\
Single & $66(27.7)$ \\
Divorced & $18(7.4)$ \\
Widowed & $13(5.5)$ \\
Living as married & $6(2.6)$ \\
Separated & $3(1.3)$ \\
\hline 7) Income $(\mathrm{n}=3274)$ & \\
$0-20,000$ & $21(17.4)$ \\
$20,000-34,999$ & $32(11.5)$ \\
$35,000-49,999$ & $37(15.5)$ \\
$50,000-74,999$ & $30(12.6)$ \\
$75,000-99,999$ & $34(14.4)$ \\
$100,000-199,999$ & $13(5.3)$ \\
$200,000+$ & \\
\hline
\end{tabular}

*Unweighted sample sizes are reported.

***Weighted sample sizes (in millions) and percentages are reported.

Furthermore, $8.5 \%$ of the participants affirmed that they had received a cancer diagnosis in their lifetime. The self-assessed health related question (HD01 General Health) had possible responses poor, fair, good, very good, and excellent. The distribution of the answers was 2, 10.7, $38,34.3$, and $12.7 \%$ respectively. The opinion-based question regarding the effects of habits and behaviors on high blood pressure is a unidirectional 4-level scale $(1,2,3,4)$ where an increase in value indicates a stronger belief in the question (starting with no belief and increasing to strongly agreeing). Those who reported that they didn't believe habits and behaviors affected high blood pressure made up $2.3 \%$ of the weighted population. $5.6 \%$ reported that they "a little" believed there was an impact, $24.6 \%$ "somewhat" believe there is a relationship, and $64.3 \%$ believe "a lot" that behaviors and habits can affect high blood pressure. The variable Sunscreen is also a unidirectional record of how often a person will wear sunscreen if they are going to be outside on a warm, sunny day. Those who said that they will "Never", "Rarely", or "Sometimes" use sunscreen were $27.1,18.9,21.4 \%$ respectively. $15.7 \%$ said they "Often" used sunscreen and $12.7 \%$ said they "Always" do. Finally, $2.4 \%$ said they avoid going outdoors if it is a sunny warm day. The variable Fruit Intent tracked the intent a participant had regarding how much fruit they 
eat. $32.3 \%$ said that they wanted to eat more fruit or drink more fruit juice, whereas the rest either said that they merely wanted to maintain how much fruit they eat, or didn't keep track of their fruit/fruit juice consumption. Average Daily TV Games recorded the number of hours, on average, participants said they watched TV or played computer games per day over the last 30 days. Only $2 \%$ responded 0 hours, $37.3 \%$ said $1-2$ hours a day, $32.9 \%$ said $3-4$ hours on average a day, $13.2 \%$ for 5-6 hours a day, and the remaining $\sim 8.6 \%$ covered $8-24$ hours a day (albeit with very low percentages for 9 hours a day and over). The final variable records the level of agreement with the statement, "I would rather not know my chances of getting cancer." $10.1 \%$ Strongly agreed, $20.3 \%$ somewhat agree, and 27.9 and $39.3 \%$ somewhat disagreed and strongly disagreed respectively.

Table 1-2. Health related background characteristics of the survey responders (unweighted sample $\mathbf{n}=\mathbf{3 6 7 7}$ )

\begin{tabular}{|l|l|}
\hline Survey Item $^{*}$ & $\mathbf{n}(\%)^{* * *}$ \\
\hline 1) Ever had Cancer $(\mathrm{n}=3648)$ & \\
Yes & $20(8.5)$ \\
No & $216(90.8)$ \\
\hline 2) General Health (n=3557) \\
Excellent & $30(12.7)$ \\
Very good & $81(34.3)$ \\
Good & $90(38)$ \\
Fair & $25(10.7)$ \\
Poor & $5(2)$ \\
\hline 3) Health Insurance (n=3615) \\
Yes & $205(86.3)$ \\
No & $30(12.5)$ \\
\hline 4) Behaviors HighBP (How much do & \\
behaviors like smoking, diet, and & \\
exercise impact developing High Blood & \\
Pressure) (n=3516) & \\
A lot & $153(64.3)$ \\
Somewhat & $58(24.6)$ \\
A little & $13(5.6)$ \\
Not at all &
\end{tabular}




\begin{tabular}{|c|c|}
\hline \multirow[b]{2}{*}{$\begin{array}{l}\text { 5) Sunscreen (When you are outside } \\
\text { for more than an hour on a sunny day, } \\
\text { how often do you use sunscreen) } \\
(\mathrm{n}=3599)\end{array}$} & $6(2.3)$ \\
\hline & \\
\hline Don't go out on sunny days & $6(2.4)$ \\
\hline Always & $30(12.7)$ \\
\hline Often & $37(15.7)$ \\
\hline Sometimes & $51(21.4)$ \\
\hline Rarely & $45(18.9)$ \\
\hline Never & $64(27.1)$ \\
\hline $\begin{array}{l}\text { 6) Fruit Intent (Anytime in the past } \\
\text { year have you intentionally tried to:) } \\
(n=3550)\end{array}$ & \\
\hline Increase the amount of fruit & $77(32.3)$ \\
\hline Maintain the amount of fruit & $56(23.7)$ \\
\hline You haven't paid attention to how much & $98(41)$ \\
\hline $\begin{array}{l}\text { 7) Average Daily TV Games (In the } \\
\text { past } 30 \text { days, how many hours on } \\
\text { average did you spend a day watching } \\
\text { TV or playing computer games) } \\
(n=3537)\end{array}$ & \\
\hline 0 & $5(2)$ \\
\hline $1-2$ & $94(37.3)$ \\
\hline $3-4$ & $78(32.9)$ \\
\hline $5-6$ & $31(13.2)$ \\
\hline $7-8$ & $9(3.8)$ \\
\hline $9-10$ & $6(2.4)$ \\
\hline $11-15$ & $4(1.5)$ \\
\hline $16-20$ & $2(0.9)$ \\
\hline $21-24$ & $0.8(<0.01)$ \\
\hline $\begin{array}{l}\text { 8) Rather Not Know Chance (I'd } \\
\text { rather not know my chances of getting } \\
\text { cancer) }(n=3541)\end{array}$ & \\
\hline Strongly agree & $24(10.1)$ \\
\hline Somewhat agree & $48(20.3)$ \\
\hline Somewhat disagree & $66(27.9)$ \\
\hline Strongly disagree & $93(39.3)$ \\
\hline
\end{tabular}

We implemented multiple preprocessing steps and techniques that included various ways of recoding categorical variables to ensure unidirectional effects of the covariates in order to allow our model building process to have a means to measure levels of effect. 
Very low response rate $(<10)$ and non-informative categories such as: "Refused to Answer" and "Don't Know" were removed from dataset and their corresponding statistical weights were uniformly distributed among the remaining subjects in the data. It is due to this that in some cases, the percentage will not equal $100 \%$.

\subsection{Automatic Variable Selection and Statistical Analysis}

HINTS IV utilized the data collection method of list-assisted random digit dialing as well as mailin questionnaire with a natural unstratified and cluster sampling design that also made use of jackknife replicates [15]. Using generalized logistic models with jackknife parameter estimation, the survey data set was analyzed based on the complete and 50 jackknife replicate datasets. Due to their ability to generally provide unbiased parameter estimates, the resampling-based analytic approaches, such as the jackknife and bootstrap, are the preferred methods for complex survey data analyses $[16,17]$. All of the computations performed in this study were carried out using the Survey package version 3.33[18] of the $\mathrm{R}$ statistical software platform (version 3.4.2, http://www.r-project.org). We executed an extensive search through all relevant potential explanatory variables for having received a cancer diagnosis. We applied a model building process based on automatic forward selection combined with backward elimination of covariates to develop the best explanatory model, combined along with the model building approach Step AIC. This approach to detecting and assessing the effects sizes of the significant explanatory variables of the aforesaid outcome of interest is data driven and model-based. It is a greatly advantageous alternative to the common hypotheses-based analyses. The best model and the corresponding unbiased effects of the predictive variables are suspect to being questioned unless the model building process encompasses all possible potential confounders and risk factors. This, at the very least, implies considering and testing all survey items for association with the outcome variable. 
Currently, studies based on hypotheses are defined in terms of existence of either positive or negative correlations between the outcome variable of interest and select candidate covariates. These hypotheses are tested by either correlation analyses or unadjusted statistical models, both of which are susceptible to bias in the estimated effects due to unaccounted confounding. In extreme cases, such naive approaches can lead to reverse association directions and false positive, or false negative, effect findings[19].

\subsection{Results}

The extensive model-based and data driven study revealed that age, application of sun protection, the belief that habits and behaviors can affect high blood pressure, your intention of fruit intake, the average number of hours spent daily watching TV or playing video games, and the level of agreeing with the statement that "you would rather not know your chance of getting a cancer diagnosis" were the only covariates significantly associated with receiving a cancer diagnosis. Detailed outputs from the logistic regression model that describe all the relevant associations are shown in Table 1-3. 
Table 1-3. Summary results from the best explanatory logistic regression model.

\begin{tabular}{lccccc}
\hline Variable & Estimate & OR & SE & t-value & p-value \\
\hline Intercept & -5.95 & - & 0.53 & -11.161 & $<0.001$ \\
\hline Sunscreen Usage & 0.21 & 1.23 & 0.05 & 3.95 & $<0.001$ \\
\hline $\begin{array}{l}\text { Behaviors Affect } \\
\text { High BP }\end{array}$ & -0.26 & 0.77 & 0.12 & -2.16 & 0.040 \\
\hline $\begin{array}{l}\text { Rather Not } \\
\text { Know Cancer } \\
\text { Chance }\end{array}$ & -0.27 & 0.76 & 0.09 & -2.94 & 0.005 \\
$\begin{array}{l}\text { Fruit } \\
\text { Consumption } \\
\text { Intent }\end{array}$ & 0.42 & 1.52 & 0.18 & 2.30 & 0.026 \\
\hline $\begin{array}{c}\text { Age } \\
\text { Average Daily }\end{array}$ & 0.06 & 1.06 & 0.005 & 13.71 & $<0.001$ \\
\hline \begin{tabular}{l} 
TV Games in hours \\
\hline
\end{tabular} & 1.06 & 0.03 & 2.38 & 0.022 \\
\hline
\end{tabular}

As illustrated in Table 1-3, age was a significant predictor of the outcome variable of interest (p-value $<0.001$ ) with an estimated effect of 0.06 . Therefore, after controlling simultaneously for all other covariates in the model, one-year increase in age was associated with a $6 \%$ increase in the odds of having had a cancer diagnosis. Similarly, sun protection ( $\mathrm{p}$-value $<0.0001)$ is a significant predictor of the outcome variable of interest with estimated effect of 0.21 . Therefore, one category increase in degree of sunscreen usage (where never using sunscreen is the reference) was associated with a $23 \%$ increase in the odds of having had a cancer diagnosis (after exponentiating the estimate). The variable regarding how behaviors impact high blood pressure (p-value 0.004 ) has an estimated effect of -0.26 . Therefore, one category increase in degree of belief that behavior has an impact on high blood pressure was associated with a $23 \%$ decrease in the odds of having had a cancer diagnosis. Fruit intention (p-value 0.026) has an estimated effect of 0.42 . Therefore, one category increase (as defined in the variable description in Table 1-2) was 
associated with a $48 \%$ increase in the odds of having had a cancer diagnosis. The variable regarding one's agreement with the statement that "you would rather not know your chance of diagnosis", was a significant predictor of the outcome variable of interest (p-value 0.005) with estimated effect sizes of -0.27 . Indicating that one category increase in agreeing with the statement that you would not like to know the chance of getting cancer was associated with a $24 \%$ decrease in the odds of having had cancer. Average daily TV and video games was a significant predictor of the outcome variable of interest (p-value 0.022) with estimated effect sizes of 0.06 . Demonstrating that one category increase in how many hours on average you watched TV or played video games was associated with a $6 \%$ increase in the odds of having had cancer.

Lastly, the model attained an area under the AUC curve of 0.751 indicating high classification accuracy for the studies human behavior. Details shown in Figure 1-1. 
Figure 1-1. ROC Curve with $\mathrm{AUC}=0.751$

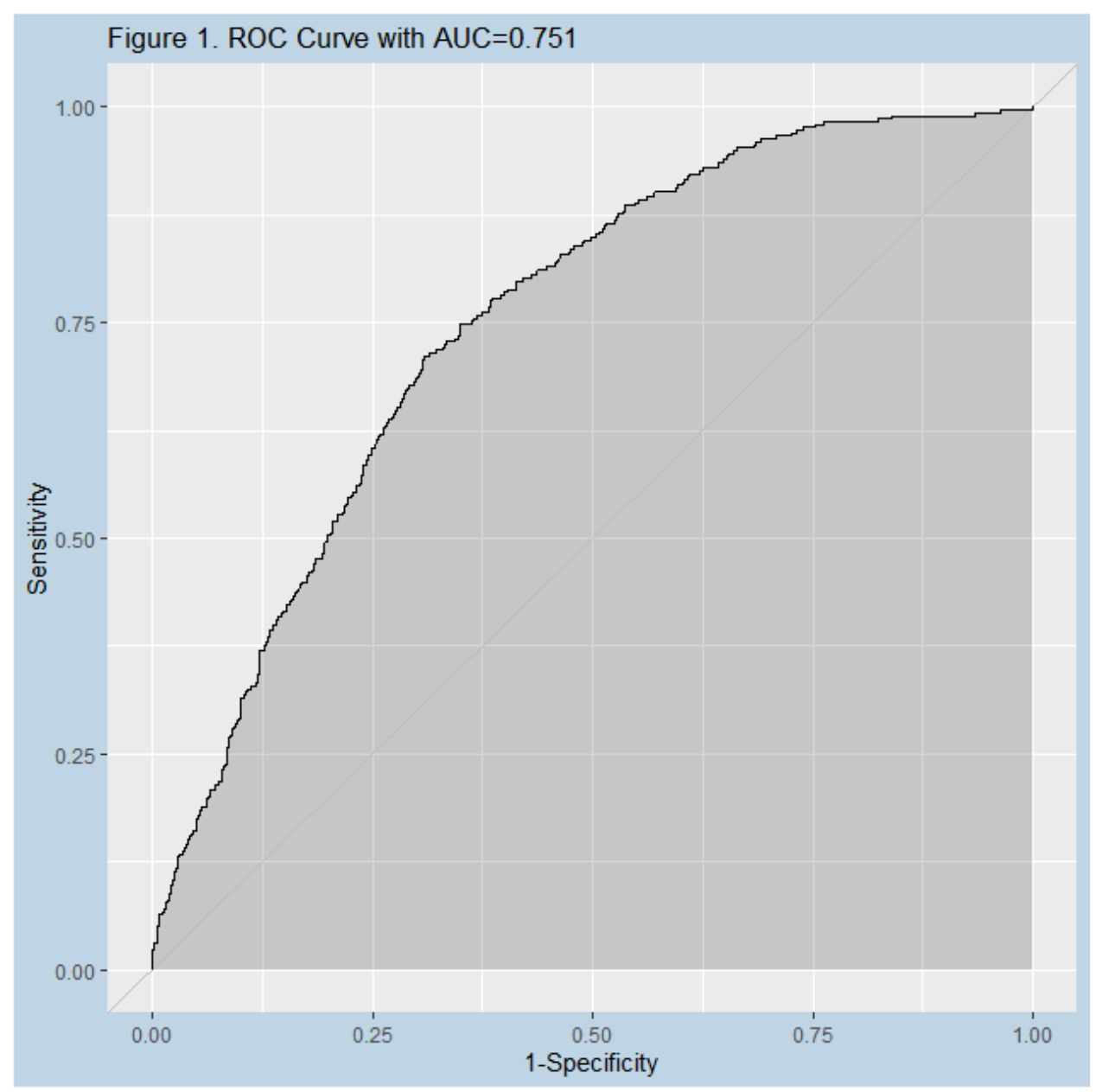

\subsection{Discussion}

The intention of this study was to investigate the differences in the behavioral characteristics that differ between people that had and did not have cancer diagnoses. The impact of a cancer diagnosis is one that can greatly affect a person and place a strain on them as well as their friends and family. A better understanding of how this can affect people can more accurately educate health care professionals on what to address and make clearer for their patients. This would 
make the entire process more open and accessible for most patients, which could in turn better prepare them for what to expect, what certain originally unknown terms, phrases, and acronyms mean, and how to better handle and address their condition and treatment. This is paramount, as a positive mindset is one of the best techniques in helping patients through treatments. As a result, this will help dispel some of the fear and confusions of this situation. It could also potentially assist healthcare professionals in new aspects of what to be aware of as signs for possible cancer indicators.

In this study, we analyzed the 2014 HINTS dataset (Cycle 4) which tracks the trends of public opinions regarding health and health care organizations. This dataset is a survey of over 3600 people who were collectively chosen to be representative of the entire US population. The data required extensive pre-processing due to missing variable issues and collinearity. We designed and implemented a novel method of analysis that combined automatic variable selection and logistic regression modeling that incorporated sampling weights and jackknife replicate weights. The novel approach identified the best explanatory model that included new variables that provide valuable insight into the behavioral differences between people with and without cancer diagnosis. In particular, the best explanatory model included six variables, how often sunscreen is used on sunny days, how strongly an individual believes that behaviors and lifestyle can affect a diagnosis of high blood pressure, the average daily time spent watching TV or playing video games, how strongly a participant agrees with the statement of their rather not knowing their chance of getting cancer, participants intention regarding fruit consumption, and age.

The direction of the effects of some of these variables seems to be somewhat counterintuitive and we provide possible explanations as to why they are disadvantageous or protective. For instance, one would assume sunscreen usage could be a preventative measure to 
protect health and maintain skin well-being. However, it could hint that the participant feels there is a reason they need to be extra-careful due to family medical history. Moloney (2005) [20] it was stated that patients who received transplants, mentioning renal or skin grafts, had an increased chance of skin cancer. This is most likely due to being on immunosuppressants, as well as having poor sun protection habits. It is possible that improper use of sunscreen could also incorrectly make it appear that sunscreen leads to a cancer diagnosis[21]. There has also been recent speculation that in the United States, certain Ultraviolet rays are not protected against by sunscreen, leading to exposure when individuals think they are protected. As expected, the belief that one's lifestyle is affecting their diagnosis of having high blood pressure shows a lower chance of having had a cancer diagnosis. This could potentially be illustrating that the more educated and knowledgeable a person is regarding health, the more capable they are to properly care for themselves and make better choices. Participants agreeing more strongly with the statement that they would rather not know their chances of getting cancer were less likely to have had a cancer diagnosis. This lack of awareness is less prominent among cancer survivors as they realize the benefits of risk assessment and early intervention. Further, stronger intention to consume fruit or fruit juice was associated with having had a cancer diagnosis. This could signify that the participant wanted to adopt a healthier lifestyle for some specific reason and were conscious of their diet. Also, a larger number of hours a participant spent watching TV or playing video games a day was associated with having had a cancer diagnosis. Finally, age is the most commonly identified risk factor for having had a cancer diagnosis, this is not surprising as this result is wellknown.

It should be noted that certain variables which were highly expected to be predictors were not selected in the final model. There could be possible reasons why this is the case. All smoking 
variables were left out of the model despite it being well known that smoking and cancer have a strong connection. However, our outcome variable asks whether a participant has ever had cancer of any kind. This means that cancers with higher prevalence in the data may not have connection to smoking. Cancers such as skin cancer, bladder cancer, and prostate cancer would outweigh lung cancer and therefore cause smoking to not be selected for the model. This is supported by the fact that smoking variables were forced into the model, but these variables were not significant in the final model. Other health variables could have been skewed by response bias in regard to participants knowingly or unknowingly responding with false information, or indeed not responding at all. Despite the information being anonymous, participants could have answered health-based questions with less accuracy, or even unknowingly answered incorrectly due to lack of knowledge.

Our result provides new knowledge to assist healthcare professionals and patients about concerns and lifestyle changes after cancer diagnosis.

\section{Out-of-site migration rate estimation using pseudo-tagged longitudinal data}

Intertidal regions are one of the most accessible marine habitats with trends and changes that can occur monthly, yearly, or over a period of years. The accessibility of these areas puts these zones in danger of adverse human involvement. Tracking changes to these areas over a long period of time, at regular intervals, to determine if they are natural changes or human influenced changes is vital to determine what harm is being done, and possibly what changes are occurring in the environment. Limpets (lottia gigantea) are a perfect organism to study as they are a territorial species, whose activities redistribute algae and invertebrates, resulting in landscaping the ecology

of their habitat. Reliably tracking changes in the survival of local populations can help give the 
ability to identify early warning signs of climate-change related effects on the intertidal and, by extension, all of the southern California coastal waters.

We designed a novel study aimed at estimating the combined out-of-site migration/mortality (MM) as well as the on-site migration rates of limpets. This is a straightforward question if the animals are tagged. In this analysis the limpets were not tagged but the same location was visited every six months over a twenty-year period and the lengths of all limpets present at the time were recorded. The limited mobility of limpets induces a pseudo-tagged design.

The proposed method consists of three steps. First, we estimate separate linear models for six-month period growth for limpets of all sizes for low and high-density settings using an external tagged data. We use these models to predict the lengths of all limpets at subsequent time points. Second, we implement a stepwise pairing procedure that probabilistically determines which limpet measurements from consecutive time periods belong to the same animal as well as which ones belong to animals that have migrated in or out/died. This is achieved by implementing logistic regression models that assign high probability that two limpet measurements from adjacent time periods $\mathrm{j}$ and $\mathrm{j}+1$ belong to the same animal, based on if the distance between this limpet's predicted length for period $\mathrm{j}+1$ using an appropriate growth model and its length at time $t$, and the closest observed length among all measurements from time $\mathrm{j}+1$ is small. This technique resembles stepwise variable selection in model building and sequentially creates pairs of matching limpet measurements and single measurements from both periods $t$ and $t+1$ that denote the out-of-site migration/mortality and on-site migration respectively. We ran the entire matching algorithm 1,000 times and averaged the out-of-site migration/mortality and on-site migration rates. 
Moreover, we averaged our results over a range of initial values for the parameters of the logistic regression models that reflect an informative prior knowledge.

Our results show that emigration/mortality, immigration and staying rates were 0.5 with a standard deviation of $0.1,0.47$ with a standard deviation of 0.15 , and 0.50 with a standard deviation of 0.1 respectively. Additionally, $44.1 \%$ of the limpets emigrated/died within the first six-month period, the average staying time was 1.97 six-month intervals and the maximum staying time was 4 years. Lastly, we found that the effect of low-density habitation settings significantly increased (p-value $<0.001$ ) the emigration/mortality by $11.1 \%$ but had no significant impact on immigration (p-value $<0.91)$.

\subsection{Introduction}

Measuring migration, growth, mortality, and other biological events are critically important statistics for life-history analyses and can be estimated in different ways. The most direct method is a longitudinal study: census identified individuals repeatedly across time, thereby documenting all aspects of their lives. For sessile organisms such as trees or barnacles individual identities are easily monitored as monitoring the position of each individual. Censusing individually identified mobile animals in this way is much more difficult inasmuch as their location from date to date is uncertain, making estimates of mortality and other life-history parameters (e.g., growth, reproduction) much less precise.

Performing longitudinal analysis on certain measurements of organisms requires repeated acquisition of data. A desired study design is to either tag the organism or set up a tracking system that can make observations regularly without needing the observer to repeatedly take measurements manually. It might even be acceptable if some identifying marks of the organisms 
can be recorded that would help identify them even without actual tagging [22]. The subsequent estimation of the parametric growth curve can be achieved through least squares [23-27].

Unlike studies of tagged animals, most studies that utilize measurements of untagged animals generally only use population averages [28]. The present study is the first to attempt to use data from an untagged population to extract individual characteristics that are critical for estimates of growth and mortality.

Thus, tag recapture approaches are often prohibitively labor intensive and other competing methods are often unacceptably inexact. We here propose a novel approach to probabilistically assess individual emigration/mortality (EM) and immigration (IM) rates of untagged longitudinally measured limpets using logistic regression models, unknown parameter integration (resembling implementation of an uninformative prior in Bayesian analysis) and a stepwise pairing procedure that tracks untagged limpets over successive time periods. We are asking whether this method can accurately reveal otherwise hidden demographic parameters such as emigration/mortality and immigration rates.

In this study we apply the proposed method to real untagged biannual data to investigate the out-of-site migration (emigration)/mortality and on-site migration (immigration) of limpets. This population of limpets resided within permanent quadrats on a cluster of rocks in Newport Beach, California over a 20-year period. These measurements were taken at six-month intervals without tagging the animals.

\subsection{Data}

Data were collected biannually on the length of a population of limpets residing on a cluster of rocks in Newport Beach, California over a 20-year period. There were 39 different timemeasurements taken, two in each year except for the first year. The number of limpets ranged from 
62 to 312 with a mean of 183 and standard deviation of 73 . In the aggregated data, shell lengths ranged from $9 \mathrm{~mm}$ to $82 \mathrm{~mm}$ with a mean of $35.1 \mathrm{~mm}$ and standard deviation of $11.7 \mathrm{~mm}$. The mode was $37 \mathrm{~mm}$ that was observed 126 times among a total of 3,654 total measurement over the years. Detailed summary statistics for aggregated data and stratified by year data are shown in Table 2-1.

Table 2-1. Summary statistics for the length of limpets.

\begin{tabular}{|c|c|c|c|c|c|c|c|}
\hline Year & Mean & SD & Median & Mode & Min & Max & $\mathrm{N}$ \\
\hline 1996 & 36.3 & 13.7 & 35 & 19 & 9 & 74 & 312 \\
\hline 1997 & 33.3 & 10.9 & 32 & 26 & 12 & 71 & 296 \\
\hline 1998 & 36.9 & 10.6 & 35 & 27 & 16 & 64 & 241 \\
\hline 1999 & 36.2 & 12.5 & 37 & 26 & 13 & 73 & 287 \\
\hline 2000 & 36.4 & 11.6 & 35 & 23 & 16 & 71 & 186 \\
\hline 2001 & 37.6 & 10.6 & 37 & 41 & 16 & 82 & 249 \\
\hline 2002 & 36.5 & 10.8 & 35 & 35 & 17 & 72 & 209 \\
\hline 2003 & 34.8 & 12.0 & 34 & 34 & 15 & 80 & 246 \\
\hline 2004 & 37.4 & 10.5 & 38 & 32 & 15 & 66 & 207 \\
\hline 2005 & 33.0 & 11.7 & 32 & 15 & 15 & 66 & 200 \\
\hline 2006 & 38.0 & 9.9 & 39 & 40 & 15 & 73 & 139 \\
\hline 2007 & 34.9 & 10.0 & 34 & 40 & 15 & 69 & 171 \\
\hline 2008 & 35.5 & 11.1 & 36 & 35 & 15 & 63 & 151 \\
\hline 2009 & 36.8 & 10.7 & 37 & 25 & 16 & 65 & 123 \\
\hline 2010 & 37.3 & 12.2 & 37.5 & 27 & 14 & 67 & 146 \\
\hline 2011 & 33.8 & 11.2 & 33 & 28 & 14 & 71 & 141 \\
\hline 2012 & 38.0 & 14.2 & 38 & 14 & 14 & 72 & 107 \\
\hline 2013 & 42.2 & 12.3 & 44 & 30 & 16 & 65 & 62 \\
\hline 2014 & 32.6 & 12.5 & 30 & 36 & 15 & 69 & 100 \\
\hline 2015 & 34.0 & 12.7 & 34 & 17 & 15 & 64 & 81 \\
\hline Overall & 35.9 & 11.7 & 35.1 & 37 & 9 & 82 & 3654 \\
\hline & & & & & & & \\
\hline
\end{tabular}

\subsection{Methods}

In the first step of our analysis we used a parametric linear growth model using external tagged data. This allowed us to predict the growth for all limpets at future time points and use these 
predictions as a foundation of the subsequent stepwise procedure for tracking limpets across adjacent time points.

\subsubsection{Parametric growth estimation}

We fitted a growth model to external length data of tagged limpets that did not contain information on emigration/mortality or immigration rates. The data consisted of 39 limpets measured over a 6-month period in multiple locations with varying population densities (from 9.4 animals $/ m^{2}$ to 21.1 animals $\left./ m^{2}\right)$. As it is well known that the growth rate of limpets depends on the population density[29]. Thus, we fitted two separate linear models for low and high population density scenarios respectively. Details are shown in Figure 2-1. The two linear equations were,

$$
\begin{aligned}
& l_{i+1, j}=20.68-0.26 l_{t, j}+\varepsilon_{i, j}, \\
& l_{i+1, j}=9.59-0.13 l_{t, j}+\varepsilon_{i, j},
\end{aligned}
$$

where $l_{t, j}$ denotes the length of the $j$-th limpet at time $i$ and $\varepsilon_{i, j} \sim N\left(0, \sigma_{\varepsilon}^{2}\right)$.

Figure 2-1. Initial shell length vs. growth after 6 months

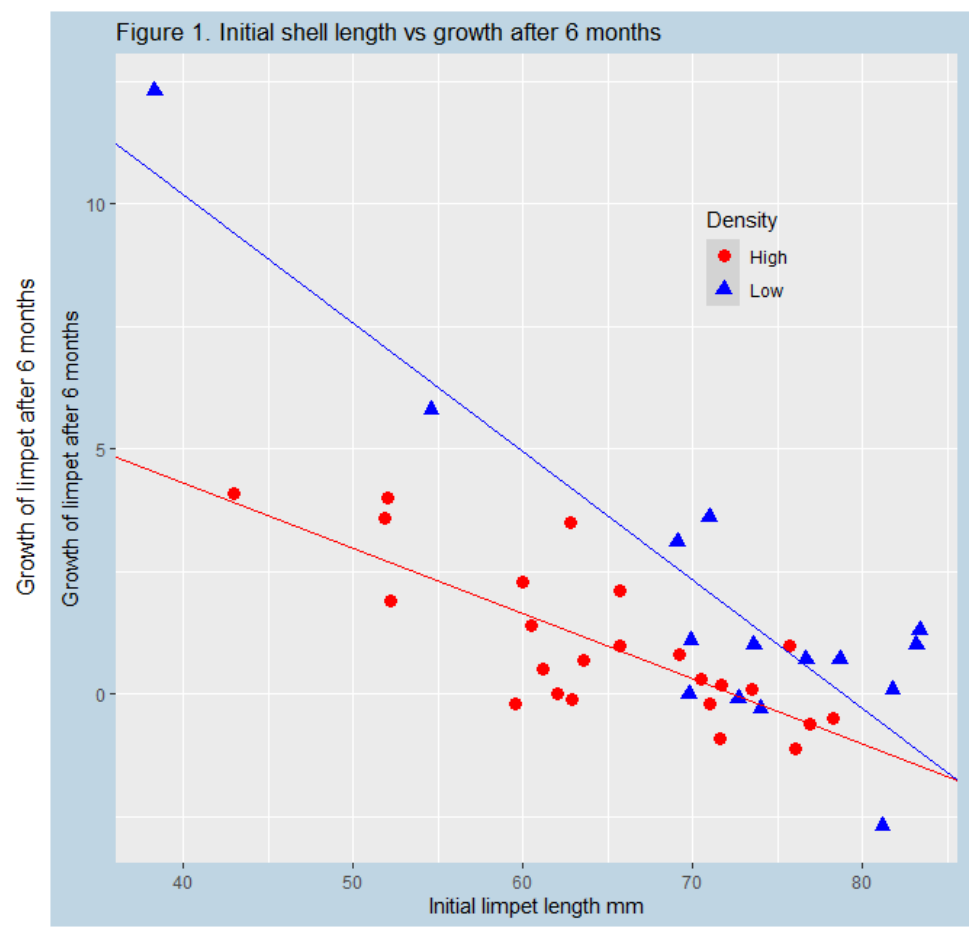




\subsubsection{Single limpet trajectory reconstruction}

Let $\hat{l}_{i+1, j}=E\left(l_{i, j} \mid G\right)$ be the forecasted length for time $i+1$ of the $j-t h$ limpet from time $i$ given a growth model $G$. Let $l_{i, j}^{i+1}$ be the measurement at time $i+1$ closest to $\hat{l}_{i+1, j}, d_{i, j}^{i+1}$ denote this minimum distance and $n_{i+1}$ denote the number of observed lengths at time $i+1$,

$$
d_{i, j}^{i+1}=\min _{1 \leq k \leq n_{i+1}}\left|l_{i+1, k}-\hat{l}_{i+1, j}\right| .
$$

We model the probability that observed lengths $l_{i, j}$ and $l_{i, j}^{i+1}$ belong to the same limpet by a logistic function,

$$
P\left(l_{i, j} \rightarrow l_{i, j}^{i+1} \mid d_{i, j}^{i+1}\right)=\frac{e^{\beta_{0}+\beta_{1} d_{i, j}^{i+1}}}{1+e^{\beta_{0}+\beta_{i} d_{i, j}^{++1}}} .
$$

We estimate the parameters $\hat{\beta}_{0}$ and $\hat{\beta}_{1}$ via two initial conditions,

$$
\begin{gathered}
P\left(l_{i, j} \rightarrow l_{i, j}^{i+1} \mid d_{i, j}^{i+1}=0\right)=\frac{e^{\beta_{0}}}{1+e^{\beta_{0}}}=p_{0}, \\
P\left(l_{i, j} \rightarrow l_{i, j}^{i+1} \mid d_{i, j}^{i+1}=\hat{\sigma}\right)=\frac{e^{\beta_{0}+\beta_{1} \hat{\sigma}}}{1+e^{\beta_{0}+\beta_{i} \hat{\sigma}}}=p_{1} .
\end{gathered}
$$

Solving equations 1.7 and 1.8 we obtain,

$$
\hat{\beta}_{0}=\ln \frac{p_{0}}{1-p_{0}}, \hat{\beta}_{1}=\frac{\ln \left[p_{1} /\left(1-p_{1}\right)\right]-\ln \left[p_{0} /\left(1-p_{0}\right)\right]}{\hat{\sigma}} .
$$

We estimated the MM for a range of the unknown initial conditions that consist of all pairwise combinations (resulting in 42 pairs) of the following values for $p_{0}$ and $p_{1}$ that reflect a lack of prior information about their true values,

$$
\left(p_{0}, p_{1}\right) \in\{0.05,0.1,0.15,0.2,0.25,0.3\} \times\{0.2,0.3,0.4,0.5,0.6,0.7,0.8\} .
$$




\subsubsection{Number of possible limpet trajectories over two successive time points}

We use the term trajectory to define a growth profile of a limpet. The number of possible animal trajectories increases very fast as the number of animals and years increases. For example, with $n$ animals and just two years of data, the number of possible trajectories is,

$$
T(n)=\sum_{k=0}^{n}\left(\begin{array}{l}
n \\
k
\end{array}\right)^{2}(n-k) !
$$

This follows from the fact that any observation in the second year can be on a trajectory starting with any observation in the first year and that any or all of the first-year observations can be ends of trajectories. The first ten values of this function are shown in Table 2-2.

Table 2-2

Growth of T(n).

\begin{tabular}{|c|c|}
\hline $\mathrm{n}$ & $\mathrm{T}(\mathrm{n})$ \\
\hline 1 & 2 \\
\hline 2 & 7 \\
\hline 3 & 34 \\
\hline 4 & 209 \\
\hline 5 & 1,546 \\
\hline 6 & 13,327 \\
\hline 7 & 130,922 \\
\hline 8 & $1,441,729$ \\
\hline 9 & $17,572,114$ \\
\hline 10 & $234,662,231$ \\
\hline
\end{tabular}

\subsubsection{Stepwise procedure for all trajectory reconstruction}

As equation (1.8) and the corresponding numbers in Table 2-2 suggest, consideration of all possible pairings of limpets even over two successive time periods is computationally impractical. Thus, we implement a stepwise procedure that is conceptually like stepwise variable selection in 
regression modeling that assigns emigration/mortality, staying and immigrations statuses to all limpets sequentially. Here is the description of this approach,

1. Set up initial conditions for logistic model that determines if two length measurements from successive time points belong to the same limpet.

2. Forecast the lengths of all limpets measured at time $\mathrm{j}$ for time $(\mathrm{j}+1)$ using the correct density-specific growth model (1.1).

3. Calculate all distances between the actual measured lengths at time $(j+1)$ and the forecasted values.

4. Choose the minimum distance from step 3 and use the model from step 1 to probabilistically assign a status (0/1) denoting if the two length measurements from these successive time points belong to the same limpet.

5. If the assigned status in step 4 is 1 , we assign a staying status of 1 to the limpet from time $(\mathrm{j}+1)$ and the stepwise procedure continues using the rest of the data.

If the assigned status in step 4 is 0 , we remove this pair as a possibility and the stepwise procedure continues, preventing these two limpets to pair up with other limpets.

6. The stepwise procedure continues until we run out of limpets from one of the two time periods or the probability of creating any further pairs drop below a threshold.

7. The entire process is repeated 1,000 times and the results averaged.

The initial conditions are changed (over a set of 42 values), the entire process is repeated, and the 42 results are averaged by 6-month interval. 


\subsubsection{Emigration/mortality, immigration, and year-to-year staying rates and staying duration estimation}

The completion of the implementation of the previous section on the stepwise procedure for all trajectory reconstruction partitions the $n_{i}$ limpets from the $i$-th time point (for all except the last) to two groups, those that stay till at least the next time point and those that emigrated or died,

$$
\left(s_{i}, e m_{i}\right), n_{i}=s_{i}+e m_{i}, i=1,2, \ldots, 38 .
$$

Additionally, we obtain the proportions of limpets that have immigrated into the population at the $i$-th time point (for all except the first),

$$
i_{i}, i=2,3, \ldots, 39
$$

Thus, we obtain time series data on all three measures that allows us to estimate the trends over time as well as summary statistics for these samples such as means, standard deviations, minima and maxima. Further, the proposed approach allows us to track limpets that stay over multiple time-measurements which allows us to obtain the distribution of the staying durations.

\subsubsection{Validation and bias estimation}

We analyzed the performance of the proposed method on simulated validation sets that arise from a range of possible settings. These settings consist of two samples of limpets residing in successive time intervals over a range of sample sizes and immigration and emigration/mortality rates. The validation set of limpets for the initial time period was randomly sampled from the distribution of lengths of the aggregated longitudinal data. Predicted limpet growths over the subsequent six-month period were obtained using the parametric growth model estimated from the tagged data that also includes normally distributed error terms. Then, for a given proportion of 
immigrated limpets, we removed a random sample of a random number of grown limpets (using a random sample from binomial distribution that adds variability of the actual number of disappearing limpets). In order to model emigration, we added to the grown limpet data a random sample of limpets of a random sample size. The settings were defined by combinations of three immigration and immigration/mortality rates of $10 \%, 20 \%, 50 \%$ and six sample sizes $50,100,150$, 200,250 , and 300 . The proposed algorithm was applied to all simulated datasets. The rates of immigration and emigration/mortality and corresponding biases were estimated. All initial conditions were used and averaged. As the true rates are unknown, resembling implementation of an uninformative prior in Bayesian analysis, we averaged the two biases within each sample size and used these averages as bias correction measures. Detailed results are shown in Table 2-3.

Table 2-3

Validation results for several scenarios.

\begin{tabular}{|c|c|c|c|c|c|c|}
\hline $\begin{array}{r}\text { Sample } \\
\text { Size }\end{array}$ & $\begin{array}{r}\text { True } \\
\text { Migrati } \\
\text { on Rate } \\
\text { In } \\
\end{array}$ & $\begin{array}{r}\text { True } \\
\text { Migrati } \\
\text { on Rate } \\
\text { Out/Mo } \\
\text { rtality }\end{array}$ & $\begin{array}{r}\text { Predi } \\
\text { cted } \\
\text { Migrati } \\
\text { on in } \\
\text { rate }\end{array}$ & $\begin{array}{r}\text { Predi } \\
\text { cted } \\
\text { Migrati } \\
\text { on } \\
\text { Out/Mo } \\
\text { rtality } \\
\text { rate }\end{array}$ & $\begin{array}{r}\text { Bias in } \\
\text { estimated } \\
\text { Migration In } \\
\text { (Bias } \\
\text { correction) }\end{array}$ & $\begin{array}{r}\text { Bias in } \\
\text { estimated } \\
\text { Migration } \\
\text { Out/Mortality } \\
\text { (Bias correction) }\end{array}$ \\
\hline 50 & 0.1 & 0.1 & 0.42 & 0.42 & $0.32(0.17)$ & $0.32(0.17)$ \\
\hline 50 & 0.1 & 0.05 & 0.45 & 0.40 & $0.35(0.17)$ & $0.35(0.17)$ \\
\hline 50 & 0.1 & 0.2 & 0.35 & 0.46 & $0.25(0.17)$ & $0.26(0.17)$ \\
\hline 50 & 0.2 & 0.2 & 0.43 & 0.43 & $0.23(0.17)$ & $0.23(0.17)$ \\
\hline 50 & 0.2 & 0.1 & 0.49 & 0.39 & $0.29(0.17)$ & $0.29(0.17)$ \\
\hline 50 & 0.2 & 0.3 & 0.37 & 0.47 & $0.17(0.17)$ & $0.17(0.17)$ \\
\hline 50 & 0.5 & 0.5 & 0.46 & 0.46 & $-0.04(0.17)$ & $-0.04(0.17)$ \\
\hline 50 & 0.5 & 0.4 & 0.52 & 0.42 & $0.02(0.17)$ & $0.02(0.17)$ \\
\hline 50 & 0.5 & 0.6 & 0.40 & 0.50 & $-0.10(0.17)$ & $-0.10(0.17)$ \\
\hline 100 & 0.1 & 0.1 & 0.39 & 0.39 & $0.29(0.14)$ & $0.29(0.14)$ \\
\hline 100 & 0.1 & 0.05 & 0.42 & 0.37 & $0.32(0.14)$ & $0.32(0.14)$ \\
\hline 100 & 0.1 & 0.2 & 0.33 & 0.43 & $0.23(0.14)$ & $0.23(0.14)$ \\
\hline
\end{tabular}




\begin{tabular}{|r|r|r|r|r|r|r|}
\hline 100 & 0.2 & 0.2 & 0.40 & 0.40 & $0.20(0.14)$ & $0.20(0.14)$ \\
\hline 100 & 0.2 & 0.1 & 0.47 & 0.37 & $0.27(0.14)$ & $0.27(0.14)$ \\
\hline 100 & 0.2 & 0.3 & 0.34 & 0.44 & $0.14(0.14)$ & $0.14(0.14)$ \\
\hline 100 & 0.5 & 0.5 & 0.43 & 0.43 & $-0.07(0.14)$ & $-0.07(0.14)$ \\
\hline 100 & 0.5 & 0.4 & 0.49 & 0.39 & $-0.01(0.14)$ & $-0.01(0.14)$ \\
\hline 100 & 0.5 & 0.6 & 0.37 & 0.47 & $-0.13(0.14)$ & $-0.13(0.14)$ \\
\hline 150 & 0.1 & 0.1 & 0.38 & 0.38 & $0.28(0.12)$ & $0.28(0.12)$ \\
\hline 150 & 0.1 & 0.05 & 0.41 & 0.36 & $0.31(0.12)$ & $0.24(0.12)$ \\
\hline 150 & 0.1 & 0.2 & 0.32 & 0.42 & $0.22(0.12)$ & $0.06(0.12)$ \\
\hline 150 & 0.2 & 0.2 & 0.39 & 0.39 & $0.19(0.12)$ & $0.16(0.12)$ \\
\hline 150 & 0.2 & 0.1 & 0.45 & 0.35 & $0.25(0.12)$ & $0.18(0.12)$ \\
\hline 150 & 0.2 & 0.3 & 0.33 & 0.43 & $0.13(0.12)$ & $0.04(0.12)$ \\
\hline 150 & 0.5 & 0.5 & 0.40 & 0.40 & $-0.10(0.12)$ & $-0.02(0.12)$ \\
\hline 150 & 0.5 & 0.4 & 0.46 & 0.36 & $-0.04(0.12)$ & $-0.27(0.12)$ \\
\hline 150 & 0.5 & 0.6 & 0.34 & 0.44 & $-0.16(0.12)$ & $0.05(0.12)$ \\
\hline 200 & 0.1 & 0.1 & 0.37 & 0.37 & $0.27(0.11)$ & $0.27(0.11)$ \\
\hline 200 & 0.1 & 0.05 & 0.40 & 0.35 & $0.30(0.11)$ & $0.30(0.11)$ \\
\hline 200 & 0.1 & 0.2 & 0.31 & 0.41 & $0.21(0.11)$ & $0.21(0.11)$ \\
\hline 200 & 0.2 & 0.2 & 0.38 & 0.38 & $0.18(0.11)$ & $0.18(0.11)$ \\
\hline 200 & 0.2 & 0.1 & 0.44 & 0.34 & $0.24(0.11)$ & $0.24(0.11)$ \\
\hline 200 & 0.2 & 0.3 & 0.32 & 0.42 & $0.12(0.11)$ & $0.12(0.11)$ \\
\hline 200 & 0.5 & 0.5 & 0.38 & 0.38 & $-0.12(0.11)$ & $-0.12(0.11)$ \\
\hline 200 & 0.5 & 0.4 & 0.44 & 0.34 & $-0.06(0.11)$ & $-0.06(0.11)$ \\
\hline 200 & 0.5 & 0.6 & 0.32 & 0.42 & $-0.18(0.11)$ & $-0.18(0.11)$ \\
\hline 250 & 0.1 & 0.1 & 0.29 & 0.29 & $0.19(0.04)$ & $0.19(0.04)$ \\
\hline 250 & 0.1 & 0.05 & 0.32 & 0.27 & $0.22(0.04)$ & $0.22(0.04)$ \\
\hline 250 & 0.1 & 0.2 & 0.23 & 0.33 & $0.13(0.04)$ & $0.13(0.04)$ \\
\hline 250 & 0.2 & 0.2 & 0.30 & 0.30 & $0.10(0.04)$ & $0.10(0.04)$ \\
\hline 250 & 0.2 & 0.1 & 0.37 & 0.27 & $0.17(0.04)$ & $0.17(0.04)$ \\
\hline 250 & 0.2 & 0.3 & 0.25 & 0.35 & $0.05(0.04)$ & $0.05(0.04)$ \\
\hline 250 & 0.5 & 0.5 & 0.32 & 0.32 & $-0.18(0.04)$ & $-0.18(0.04)$ \\
\hline 250 & 0.5 & 0.4 & 0.38 & 0.28 & $-0.12(0.04)$ & $-0.12(0.04)$ \\
\hline 250 & 0.5 & 0.6 & 0.26 & 0.36 & $-0.24(0.04)$ & $-0.24(0.04)$ \\
\hline 300 & 0.1 & 0.1 & 0.29 & 0.29 & $0.19(0.03)$ & $0.19(0.03)$ \\
\hline 300 & 0.1 & 0.05 & 0.32 & 0.27 & $0.22(0.03)$ & $0.22(0.03)$ \\
\hline 300 & 0.1 & 0.2 & 0.23 & 0.34 & $0.14(0.03)$ & $0.14(0.03)$ \\
\hline & & & & & & \\
\hline
\end{tabular}




\begin{tabular}{|r|r|r|r|r|r|r|}
\hline 300 & 0.2 & 0.2 & 0.30 & 0.30 & $0.10(0.03)$ & $0.10(0.03)$ \\
\hline 300 & 0.2 & 0.1 & 0.37 & 0.27 & $0.17(0.03)$ & $0.17(0.03)$ \\
\hline 300 & 0.2 & 0.3 & 0.24 & 0.34 & $0.04(0.03)$ & $0.04(0.03)$ \\
\hline 300 & 0.5 & 0.5 & 0.31 & 0.31 & $-0.19(0.03)$ & $-0.19(0.03)$ \\
\hline 300 & 0.5 & 0.4 & 0.38 & 0.28 & $-0.12(0.03)$ & $-0.12(0.03)$ \\
\hline 300 & 0.5 & 0.6 & 0.25 & 0.35 & $-0.25(0.03)$ & $0.25(0.03)$ \\
\hline
\end{tabular}

Our results show that on average the proposed procedure slightly overestimates the emigration/mortality and immigration rates with biases between 0.36 and -0.16 and 0.30 and -0.27 respectively. The average biases for both emigration/mortality and immigration stratified by the sample size were $0.17,0.09,0.02,0.07,-0.02,0.08$ and $0.17,0.09,0.07,0.07,0.03,0.08$ respectively. These estimated biases are likely artifacts of the small sample of the validation study and the variability of the estimates of emigration/mortality and immigration rates due to the initial conditions diversity. Thus, we will not implement bias correction to adjust our results.

\subsection{Results}

After running our method using all 42 initial value combinations 1,000 times each we averaged the results to obtain $\left(s_{i}, e m_{i}\right), i=1,2, \ldots, 38$ and $i m_{i}, i=2,3, \ldots, 39$. The complete data are shown in Table A-1 in the Appendix. Time series plots of the proportions of limpets that stayed on-site and immigrated over time are shown in Figure 2-2. These two time series are stationary with Augmented Dickey-Fuller test $p$-values $<0.01$ indicating that there are changes of the mean and the variance and correlation structures over time. The best ARIMA models that fit these processes are AR and white noise respectively which can be used to forecast these rates into the future. 
Figure 2-2. Estimated proportions of limpets that stayed and immigrated over time

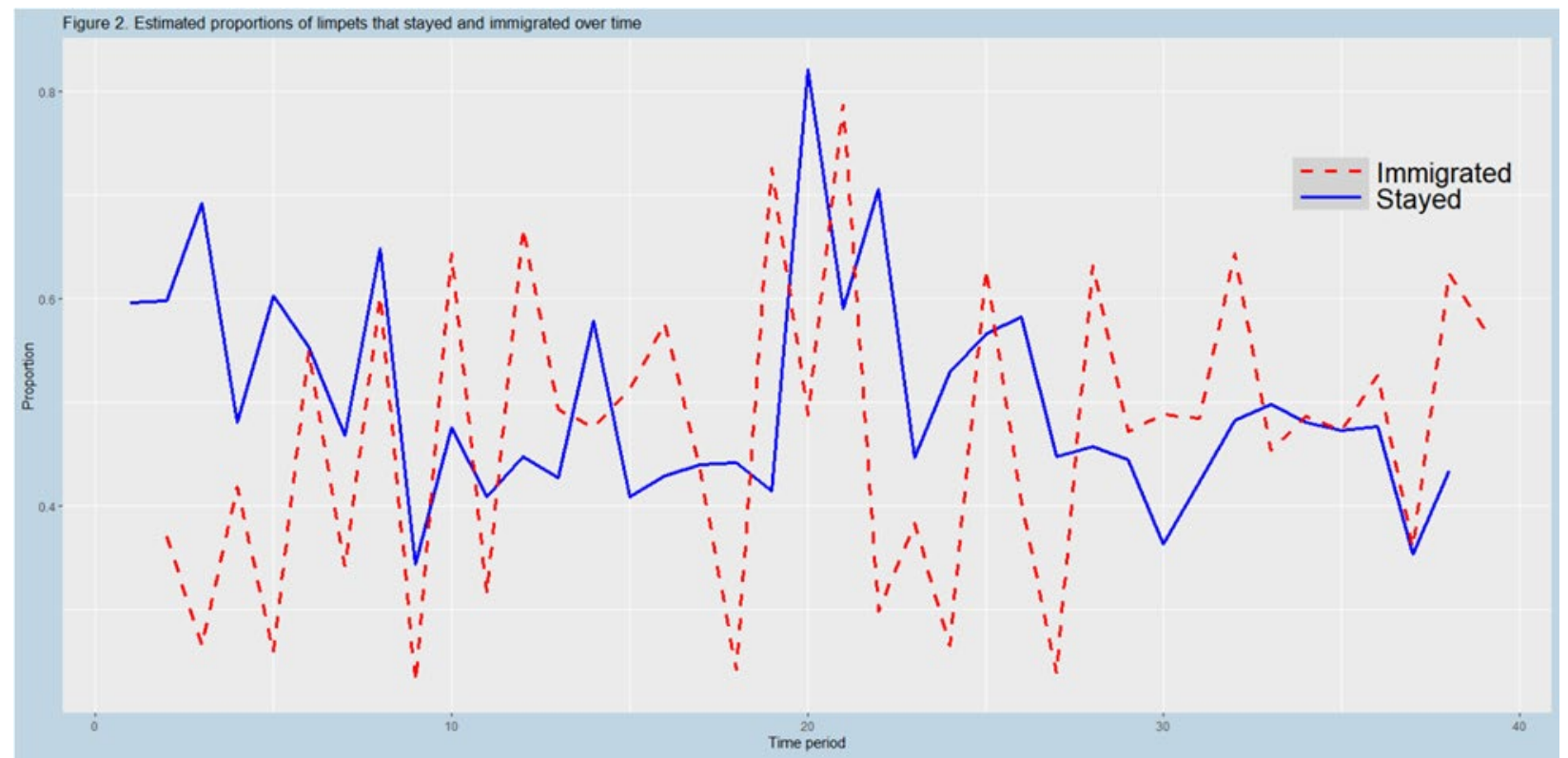

The estimated trends over time as well as summary statistics for these samples such as means, standard deviations, minima and maxima. Further, the proposed approach allows us to track limpets that stay over multiple time-measurements which allows us to obtain the distribution of the at-site staying durations (Figure 2-3). 


\section{Figure 2-3. Forecasted staying and immigration proportions}

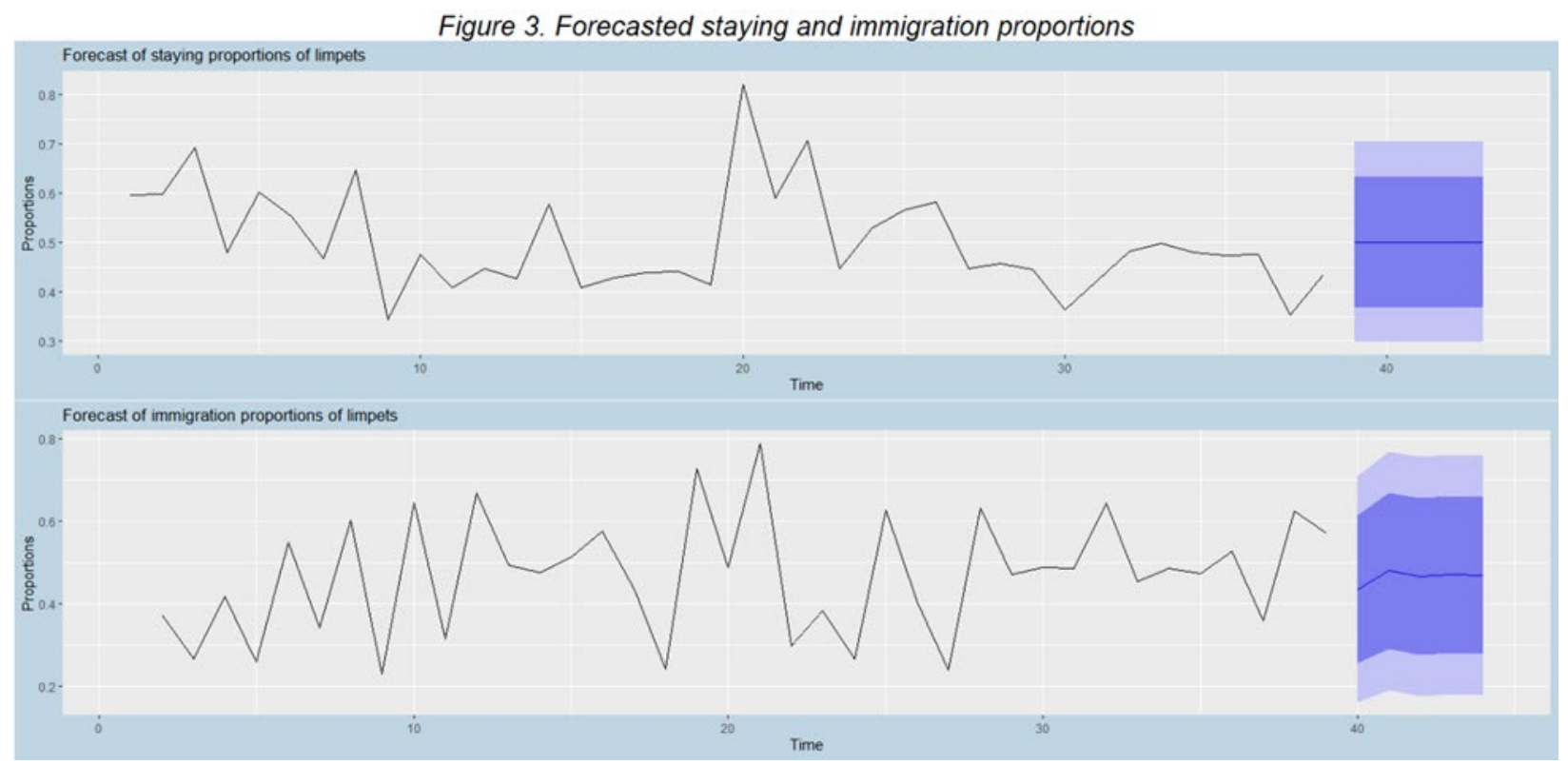

Further, averaged over the entire 20-year period, the limpets that stayed on-site over a 6month period was $50 \%$ with standard deviation of $10 \%$. The minimum and maximum rates were $34 \%$ and $82 \%$ receptively. Similarly, averaged over the entire 20 -year period, the limpets that immigrated in was $47 \%$ with standard deviation of $15 \%$. The minimum and maximum were $23 \%$ and $79 \%$ receptively.

Next, our results provide estimate of the distribution of the length of stay of limpets at the site. The number of limpets that stayed at-site declines over time with the largest percent of limpets $44.1 \%$ emigrating/dying within 6 months and $28.8 \%$ staying for only one 6 -month period. No limpet stayed at-site for more than four years. Detailed results are shown in Table 2-4. 
Table 2-4. Distribution of at-site staying durations.

\begin{tabular}{|c|c|c|}
\hline $\begin{array}{c}\text { Time in 6- } \\
\text { month periods }\end{array}$ & $\begin{array}{c}\text { Number of limpets at location, } \\
\text { averaged over all initial conditions } \\
\text { and simulation iterations }\end{array}$ & $\begin{array}{c}\text { Percent of limpets at location, } \\
\text { averaged over all initial conditions } \\
\text { and simulation iterations }\end{array}$ \\
\hline 0 & 1615 & 44.1 \\
\hline 1 & 1053 & 28.8 \\
\hline 2 & 620 & 17.0 \\
\hline 3 & 242 & 6.6 \\
\hline 4 & 78 & 2.1 \\
\hline 5 & 30 & 0.8 \\
\hline 6 & 11 & 0.3 \\
\hline 7 & 4 & 0.1 \\
\hline 8 & 1 & 0.03 \\
\hline$\geq 9$ & 0 & 0.0 \\
\hline
\end{tabular}

Additionally, we found that the effect of low-density habitats significantly increased (pvalue $<0.001)$ the emigration/mortality rates by $11.1 \%$ but had no significant impact on immigration (p-value $<0.91$ ). 
Figure 2-4. Estimated limpet growth trajectories over all 20 years.

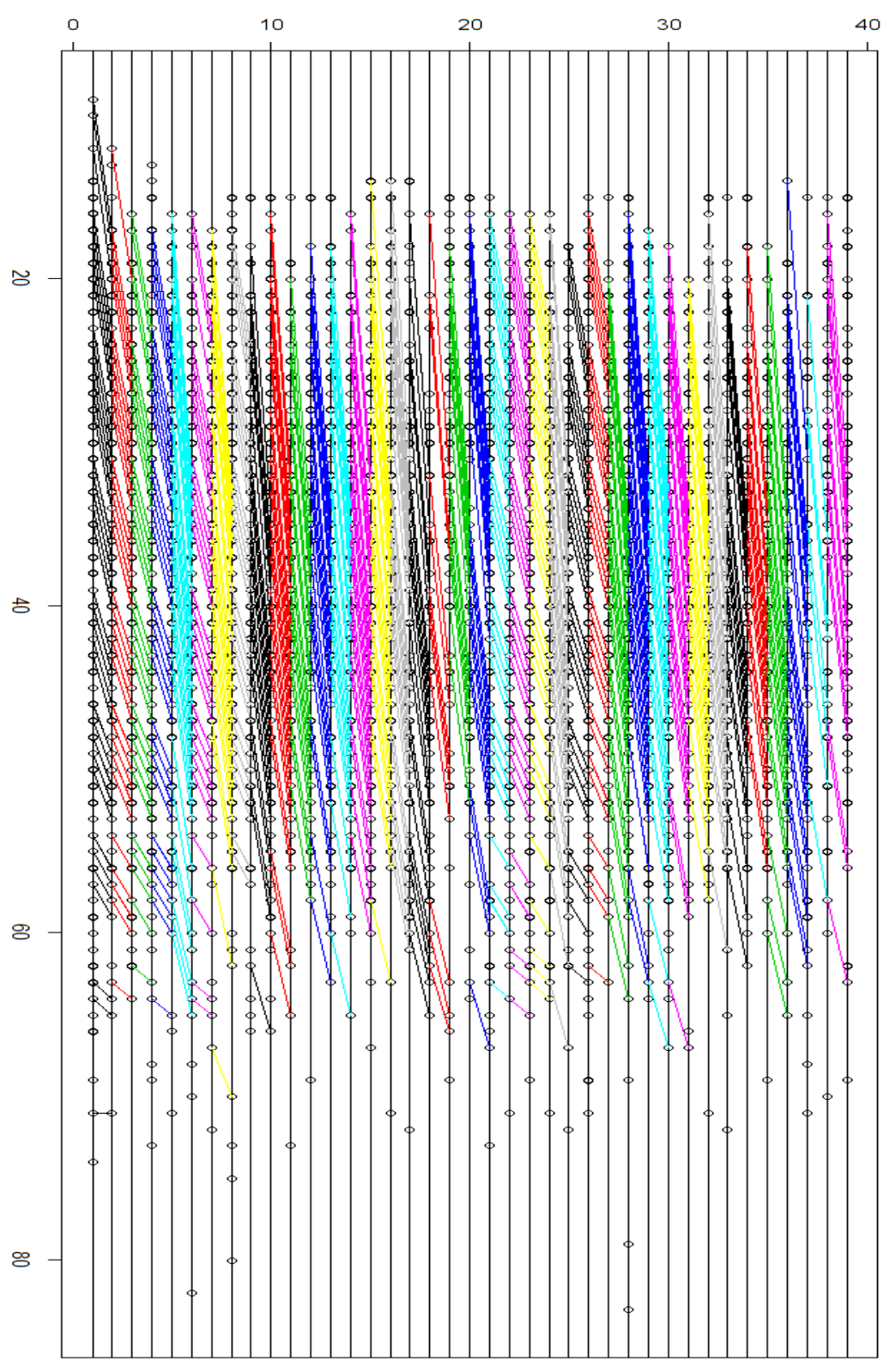


Figure 2-5. Following a sample of limpets until all are out of the data.

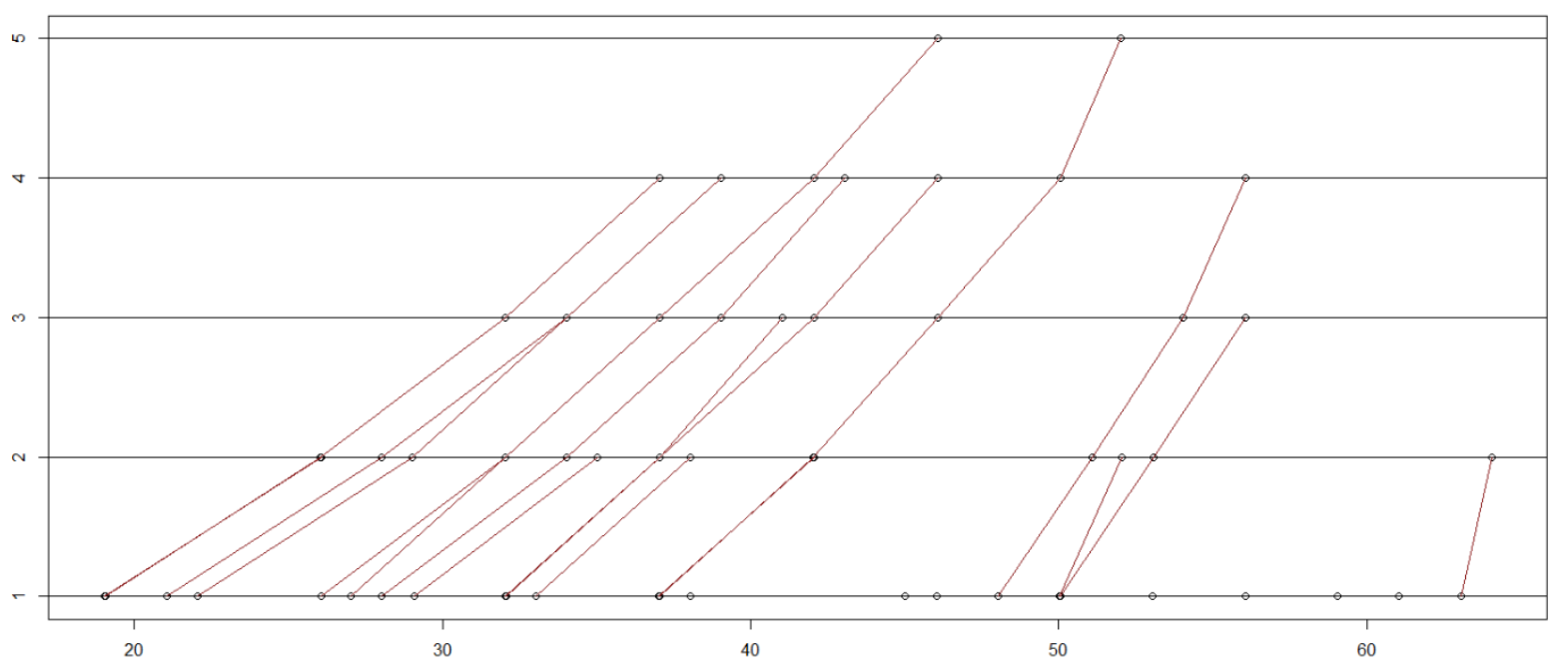

Figure 2-4 display the limpets growth lines over all 20 years. Each circle is a limpet and each line connecting a circle in one 6-month interval to a circle in the next indicates that this is the same limpet as well as how much it has grown. Each 6-month time interval is a different color for ease of viewing. Figure 5 shows the growth trajectories of a random sample of limpets from the first time-measurement followed until all in the sample emigrated or died for ease of viewing.

We can see from this figure that there are many small or juvenile limpets that grow up into the midsize, but the amount that last from midsize to larger limpets is less, with the amount that last from larger limpets to the largest limpets dropping off dramatically. We also found that the largest limpets do not carry over from one time-measurement to the next. This can be due to migration (competition, poor environment, etc.) or death (poaching, predators, debris, etc.). 
We can also see that there are limpets in the second time-measurement with the same length that go to two different lengths in the next time-measurement. This is due to "competition" in the model with limpets being paired with their best fit limpet in the next time-measurement. A limpet might not have good options to grow into, but might still be able to reach a certain length (either not growing very much or growing much more than normal) which helps display the randomness in a system.

\subsection{Discussion}

We carried out a study focused on estimating the emigration/mortality, staying and immigration rates for limpets based on pseudo tagged longitudinal data. We designed and implemented a novel multi-step algorithm to handle the uncertainty induced by the missing tags via a combination of analytical tools, a model-based prediction of growth, a logistic regression model that assigns probabilities of matching to all pairs, and a stepwise procedure that sequentially assigns pairing statuses. Further, due to the probabilistic assignments of pairings, we carried out the algorithm 1000 times and averaged the results. Additionally, we analyzed and averaged the results over 42 sets of initial conditions that in turn define different coefficients of the logistic regression model. We also implemented a validation simulation study to analyze the accuracy of our algorithm over a range of distinct settings. We have found a minor overestimation of the emigration/mortality and immigration rates. Our results show that emigration/mortality, immigration and staying rates were $0.5,0.47$, and 0.50 with a standard respectively. The average percentage of limpets that remain at-site over a 6-month period was $55.9 \%$ with the remaining $44.1 \%$ of the limpets emigrating/dying within the first six-month period. The average staying time was 1.97 six-month intervals and the maximum staying time was 4 years. Lastly, low-density 
habitation significantly increased the emigration/mortality by $11.1 \%$ but had no significant impact on immigration.

\section{Epidemiology of 72-hour Emergency Department readmission}

Return visits to the Emergency Department are a burden and a risk to patients. Respiratory conditions can deteriorate health, and numerous visits can leave these conditions untreated. The primary goal of the study is to determine previously unreported risk factors of Emergency Department return visits within 72 hours. The secondary goal is to provide a predictive model and assess its performance and considerations for implementation of the model. We utilized a nested mixed effects model combined with forward variable selection to determine the important variables predicting a return to the Emergency Department. 20 variables were found to be significant predictors of a return visit to the Emergency Department. Demographic variables such as age, race, and sex were found to be significant, as well as pseudo-socioeconomic variables such as who/what paid for the visit. There were six respiratory variables associated with a return visit. Among these, the variable 'intraoperative and postprocedural complications and disorders not classified elsewhere' was associated with a $21 \%$ increase in odds of a return visit. The rest were found to be associated with a decrease in odds of a return visit. In order to reduce the burden to patients and overcrowded Emergency Departments, reducing the number of return visits is critical. We identified novel risk factors that can improve the efficiency of the Emergency Department.

\subsection{Introduction}

The burden of respiratory diseases on patients is multifaceted including clinical, social, economic, and psychological impact [30-38]. Patients who experience deterioration often require 
emergency department (ED) care, and subsequent hospitalization in some cases, to help mitigate and control the underlying condition. This deterioration or need for emergent care may be triggered by ambient fine particulate matter, smoke from wildfires, heat waves, cold spells, and passive smoking among others [38-47]. The most prevalent and morbid respiratory diseases are chronic obstructive pulmonary disease (COPD) and asthma $[48,49]$. On the one hand, it is estimated that over 65 million people have moderate to severe COPD and about 3 million deaths are attributed to it worldwide. On the other hand, it is estimated that 334 million people suffer from asthma with rising prevalence $[50,51]$. Overall, $10 \%$ of all disability-adjusted life-years (DALYs) - a metric estimating the amount of active and productive life lost due to a condition - is attributable to respiratory diseases [52]. Treatment and control of respiratory diseases is therefore important and has been a focus of healthcare institutions.

A quality of care measure in emergency medicine and among patients with respiratory conditions is the rate of ED return visits within 72 hours[53-55] where it is estimated that over $32 \%$ are preventable [55]. These return visits further burden the patient as well as the ED and as a result require attention. Identification of risk factors for identifying patients with respiratory conditions most likely to have a return visit can be used in the development of intervention plans. Furthermore, models for predicting these high-risk patients may help clinical teams focus resources aimed at reducing return visits on the most at-risk patients and patients whose outcomes are more likely to be improved. Several studies have addressed these concerns[53, 55-57] but there is still need for improvement in the identification of risk factors and development of prediction (statistical or machine learning) models. The primary goal of this study is to determine novel (previously unreported) risk factors of return visits within 72 hours (simply referred to as "return 
visits" from here on). The secondary goal is to provide a prediction model and assess its performance and considerations for implementation of the model.

\subsection{Methods}

This study was approved by CHOC Children's Hospital Institutional Review Board (IRB 180857). The data source for this study is the Cerner Health Facts Database (referred to as Health Facts DB from here on). The Health Facts DB consists of data captured by Cerner Corporation from over 100 US healthcare systems and over 650 facilities (in 2018) that is aggregated and organized into consumable datasets to facilitate research and reporting. It consists of clinical database tables with data on patient demographics, encounters, medications, laboratory tests, clinical events, and diagnoses among others.

We retrieved all emergency department visits of adult patients (18 years or older) for any respiratory condition as defined and captured by the International Classification of Diseases, Tenth Revision, Clinical Modification (ICD-10-CM) codes J00-J99. We included data from EDs that have seen sufficiently large number of patients (for any condition) and who were discharged home from the ED. We set, a priori, the cut-off for the number of encounters required to include an ED in the study at 10,000. In addition, we retrieved available data on demographics (age, sex, and race/ethnicity), proxies for socioeconomic status (health insurance payer), and health care utilization variables. The health care utilization variables we retrieved were informed by findings in hospital readmission [58-60], for which we hypothesized will have shared risk factors with return visits to the ED. These include utilization in the prior 6 months of the index ED visit for previous ED visits and the maximum length of stay of the visits, and hospitalizations. For each visit of each patient, we determined whether there was a return visit within 72 hours of discharge from the ED as the outcome variable. We introduced two related variables not to be confused with 
the outcome variable: a variable counting the history of return visits within the prior 6 months (not counting the index ED visit), and another variable checking to see if the index visit was a return visit of an earlier encounter. The selection of these variables were again informed by previous findings $[58,59]$ in the related problem of hospital readmissions.

We retrieved 20 classes of respiratory diseases/conditions such as pneumonia, emphysema, asthma, and acute lower respiratory infections. Previous studies have indicated that the burden of respiratory conditions is further exacerbated by the presence of comorbidities[53,61]. As a result, we retrieved data on other systems of diagnoses for which the patient was treated for such as Diseases of the digestive system, Disease of the circulatory system, and Diseases of the nervous system as variables to account for during model development. We retrieved data on surgical procedures on the Integumentary, Musculoskeletal, Respiratory, Cardiovascular, Digestive, Urinary/reproductive, Endocrine, Auditory, Hemic/Lymphatic, Mediastinum/Diaphragm, and Nervous System. We created a variable counting the number of the body systems (type of surgery) for which a surgical procedure was performed. Lastly, we counted the total number of medications administered during the ED visit and the season of the ED encounter (Winter, Summer, etc.).

We included a priori constraint on the variables we retrieved/created for this study by ensuring that all variables (such as a diagnosis) is met by at least one in every thousand patients. This constraint is meant to mitigate problems due to statistical separation[62] that could lead to unstable models and infinite odds ratios. We split the data into two equal halves for model development and evaluation of model performance respectively. We provide summary statistics on the training dataset in Table 3-1.

Mixed effects models are standard statistical methods for analysis of multicenter or multi-level datasets. As a result, we built a nested random intercept model, using return to the ED within 72 
hours as the response variable, and the Hospital ID and Patient ID as the hierarchy or random variables. We performed variable selection using forward stepwise variable selection procedure with the Akaike Information Criteria as the model discriminant statistics. We provide area under the curve as a measure of the performance of the model. Analyses were carried out using Apache Spark[63] and The R Statistical Programming Language[64] as well as the generalized linear mixed effect package in R, lme4[65].

Table 3-1. Summary statistics

\begin{tabular}{|c|c|c|c|c|}
\hline Variable & Levels & $\begin{array}{r}\text { Did not return } \\
\text { within } 72 \text { hours } \\
\text { n }(\%) \text { or mean } \\
(\mathrm{sd})\end{array}$ & $\begin{array}{r}\text { Return visits } \\
\text { within } 72 \text { hours } \\
\text { n (\%) or mean } \\
(\mathbf{s d})\end{array}$ & $\begin{array}{r}\text { unadjust } \\
\text { ed } p \\
\text { value } \\
\end{array}$ \\
\hline \multirow{3}{*}{ Age (years) } & {$[0,40)$} & $408561(46.74)$ & $16768(40.97)$ & \multirow{3}{*}{$<0.001$} \\
\hline & {$[40,60)$} & $277291(31.72)$ & $14034(34.29)$ & \\
\hline & 60 or older & $188290(21.54)$ & $10130(24.75)$ & \\
\hline \multirow{2}{*}{ Sex } & Female & $550229(62.95)$ & $24615(60.14)$ & \multirow{2}{*}{$<0.001$} \\
\hline & Male & $323913(37.05)$ & $16317(39.86)$ & \\
\hline \multirow{8}{*}{ Race/Ethnicity } & Caucasian & $538051(61.55)$ & $25549(62.42)$ & \multirow{8}{*}{$<0.001$} \\
\hline & African & & & \\
\hline & American/Black & $206704(23.65)$ & $9998(24.43)$ & \\
\hline & Native American & $28215(3.23)$ & $1579(3.86)$ & \\
\hline & Hispanic & $21079(2.41)$ & $842(2.06)$ & \\
\hline & Asian/Pacific & & & \\
\hline & Islander & $8476(0.97)$ & $246(0.60)$ & \\
\hline & Other/Unknown & $71617(8.19)$ & $2718(6.64)$ & \\
\hline \multirow{6}{*}{ Payer } & Commercial & $215852(24.69)$ & $9720(23.75)$ & \multirow{6}{*}{$<0.001$} \\
\hline & $\begin{array}{l}\text { Medicare/Medica } \\
\text { id }\end{array}$ & $373232(42.70)$ & $20079(49.05)$ & \\
\hline & Other & & & \\
\hline & governmental & $27886(3.19)$ & 1079 (2.64) & \\
\hline & Self pay & $147061(16.82)$ & $5952(14.54)$ & \\
\hline & Others & $110111(12.60)$ & $4102(10.02)$ & \\
\hline \multicolumn{5}{|c|}{ Healthcare Resource Utilization Variables } \\
\hline \multirow{4}{*}{$\begin{array}{l}\text { Length of stay } \\
\text { (hours) }\end{array}$} & {$[0,1)$} & $150017(17.16)$ & $11248(27.48)$ & \multirow{3}{*}{$<0.001$} \\
\hline & {$[1,24)$} & $721244(82.51)$ & $29560(72.22)$ & \\
\hline & 24 or more & $2881(0.33)$ & $124(0.30)$ & \\
\hline & 0 & $776916(88.88)$ & $31234(76.31)$ & $<0.001$ \\
\hline
\end{tabular}




\begin{tabular}{llrrr} 
Previous & 1 & $65109(7.45)$ & $5222(12.76)$ & \\
hospitalization & 2 & $18710(2.14)$ & $2039(4.98)$ & \\
(prior 6 months) & 3 or more & $13407(1.53)$ & $2437(5.95)$ & \\
\hline Is index visit itself & No & $838901(95.97)$ & $34642(84.63)$ & $<0.001$ \\
a return visit? & Yes & $35241(4.03)$ & $6290(15.37)$ & \\
\hline \multirow{2}{*}{ Number of } & 0 & $492160(56.30)$ & $13747(33.58)$ & \\
previous ED visits & 1 & $179370(20.52)$ & $7311(17.86)$ & $<0.001$ \\
(prior 6 months) & 2 & $81868(9.37)$ & $4307(10.52)$ & \\
& 3 or more & $120744(13.81)$ & $15567(38.03)$ & \\
\hline
\end{tabular}

Longest length of stay of previous ED visits (prior 6 months)

\begin{tabular}{|c|c|c|c|c|}
\hline & - & $1.60(3.43)$ & $3.06(5.51)$ & $<0.001$ \\
\hline \multirow{4}{*}{$\begin{array}{l}\text { Number of } \\
\text { previous return } \\
\text { visits (prior } 6 \\
\text { months) }\end{array}$} & 0 & $819613(93.76)$ & $29861(72.95)$ & \multirow{4}{*}{$<0.001$} \\
\hline & 1 & $35190(4.03)$ & $3885(9.49)$ & \\
\hline & 2 & $8746(1.00)$ & $1715(4.19)$ & \\
\hline & 3 or more & $10593(1.21)$ & $5471(13.37)$ & \\
\hline \multicolumn{5}{|c|}{ Respiratory Conditions/Diseases } \\
\hline \multirow{3}{*}{$\begin{array}{l}\text { Acute upper } \\
\text { respiratory } \\
\text { infections (J00- } \\
\text { J06) }\end{array}$} & No & $591875(67.71)$ & $31116(76.02)$ & \multirow{3}{*}{$<0.001$} \\
\hline & & & & \\
\hline & Yes & $282267(32.29)$ & $9816(23.98)$ & \\
\hline \multirow{2}{*}{ Infuenza (J09-J11) } & No & $849804(97.22)$ & $40104(97.98)$ & \multirow{2}{*}{$<0.001$} \\
\hline & Yes & $24338(2.78)$ & $828(2.02)$ & \\
\hline \multirow{2}{*}{$\begin{array}{l}\text { Pneumonia (J12- } \\
\text { J18) }\end{array}$} & No & $821886(94.02)$ & $38381(93.77)$ & \multirow{2}{*}{0.035} \\
\hline & Yes & $52256(5.98)$ & $2551(6.23)$ & \\
\hline \multirow{2}{*}{$\begin{array}{l}\text { Acute } \\
\text { broncitis/brochioli } \\
\text { tis (J20-J21) }\end{array}$} & No & $794273(90.86)$ & $38633(94.38)$ & \multirow[b]{2}{*}{$<0.001$} \\
\hline & Yes & $79869(9.14)$ & $2299(5.62)$ & \\
\hline \multirow{2}{*}{$\begin{array}{l}\text { Other diseases of } \\
\text { upper respiratory } \\
\text { tract }(\mathrm{J} 30-\mathrm{J} 39)\end{array}$} & No & $771806(88.29)$ & $37326(91.19)$ & \multirow[b]{2}{*}{$<0.001$} \\
\hline & Yes & $102336(11.71)$ & $3606(8.81)$ & \\
\hline \multirow{2}{*}{$\begin{array}{l}\text { Unspecified } \\
\text { bronchitis (J40) }\end{array}$} & No & $789185(90.28)$ & $38303(93.58)$ & \multirow{2}{*}{$<0.001$} \\
\hline & Yes & $84957(9.72)$ & $2629(6.42)$ & \\
\hline \multirow{2}{*}{$\begin{array}{l}\text { Chronic bronchitis } \\
\text { (J41-J42) }\end{array}$} & No & 872225 (99.78) & $40842(99.78)$ & \multirow{2}{*}{1} \\
\hline & Yes & $1917(0.22)$ & $90(0.22)$ & \\
\hline \multirow{2}{*}{ Emphysema (J43) } & No & 866904 (99.17) & $40216(98.25)$ & \multirow{2}{*}{$<0.001$} \\
\hline & Yes & $7238(0.83)$ & $716(1.75)$ & \\
\hline \multirow{2}{*}{$\begin{array}{l}\text { Other chronic } \\
\text { obstructive }\end{array}$} & No & $741318(84.81)$ & $30566(74.68)$ & \multirow{2}{*}{$<0.001$} \\
\hline & Yes & $132824(15.19)$ & $10366(25.32)$ & \\
\hline
\end{tabular}


pulmonary disease

(J44)

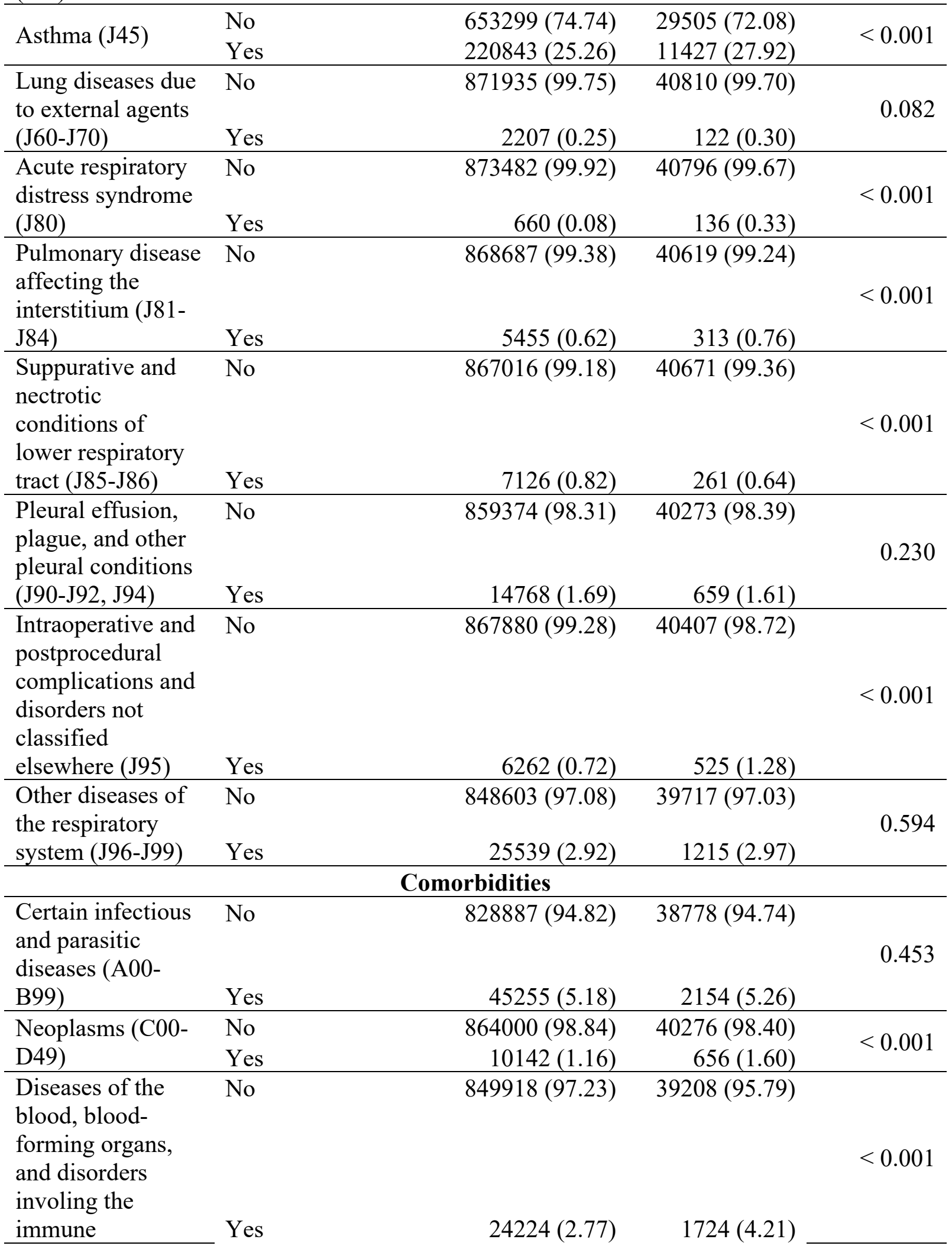


mechanism (D50-

D89)

\begin{tabular}{|c|c|c|c|c|}
\hline $\begin{array}{l}\text { Endocrine, } \\
\text { nutritional and } \\
\text { metabolic diseases } \\
\text { (E00-E89) }\end{array}$ & No & $713922(81.67)$ & $31106(75.99)$ & $<0.001$ \\
\hline $\begin{array}{l}\text { Mental, behavioral } \\
\text { and } \\
\text { neurodevelopment } \\
\text { al disorders (F01- } \\
\text { F99) }\end{array}$ & No & 677396 (77.49) & $29051(70.97)$ & $<0.001$ \\
\hline $\begin{array}{l}\text { Diseases of the } \\
\text { nervous system } \\
\text { (G00-G99) }\end{array}$ & No & $765707(87.60)$ & $\begin{array}{r}34062(83.22) \\
6870(16.78) \\
\end{array}$ & $<0.001$ \\
\hline $\begin{array}{l}\text { Disease of the eye, } \\
\text { adnexa, ear, and } \\
\text { matoid process } \\
(\mathrm{H} 00-\mathrm{H} 95)\end{array}$ & No & 819905 (93.80) & $38846(94.90)$ & $<0.001$ \\
\hline $\begin{array}{l}\text { Disease of the } \\
\text { circulatory system } \\
\text { (I00-I99) }\end{array}$ & No & $\begin{array}{l}670762(76.73) \\
203380(23.27)\end{array}$ & $\begin{array}{l}27553(67.31) \\
13379(32.69)\end{array}$ & $<0.001$ \\
\hline $\begin{array}{l}\text { Diseases of the } \\
\text { digestive system } \\
\text { (K00-K95) }\end{array}$ & No & $\begin{array}{l}778013(89.00) \\
96129(11.00) \\
\end{array}$ & $\begin{array}{r}35133(85.83) \\
5799(14.17) \\
\end{array}$ & $<0.001$ \\
\hline $\begin{array}{l}\text { Diseases of the } \\
\text { skin and } \\
\text { subcutaneous } \\
\text { tissue (L00-L99) }\end{array}$ & No & $846878(96.88)$ & $38621(94.35)$ & $<0.001$ \\
\hline $\begin{array}{l}\text { Diseases of the } \\
\text { musculoskeletal } \\
\text { system and } \\
\text { connective tissue } \\
\text { (M00-M99) }\end{array}$ & No & $745423(85.27)$ & $33510(81.87)$ & $<0.001$ \\
\hline $\begin{array}{l}\text { Diseases of the } \\
\text { genitourinary } \\
\text { system (N00-N99) }\end{array}$ & $\begin{array}{l}\text { No } \\
\text { Yes }\end{array}$ & $\begin{array}{r}809252(92.58) \\
64890(7.42) \\
\end{array}$ & $\begin{array}{r}36899(90.15) \\
4033(9.85) \\
\end{array}$ & $<0.001$ \\
\hline $\begin{array}{l}\text { Pregnancy, } \\
\text { childbirth and the } \\
\text { puerperium (O00- } \\
\text { O9A) }\end{array}$ & No & $860721(98.46)$ & $40175(98.15)$ & $<0.001$ \\
\hline $\begin{array}{l}\text { Congenital } \\
\text { malformations, } \\
\text { deformations and } \\
\text { chromosomal } \\
\text { abnormalities } \\
\text { (Q00-Q99) }\end{array}$ & No & $871741(99.73)$ & 40794 (99.66) & 0.021 \\
\hline
\end{tabular}




\begin{tabular}{|c|c|c|c|c|}
\hline $\begin{array}{l}\text { Injury, poisoning } \\
\text { and certain other } \\
\text { consequences of } \\
\text { external causes } \\
\text { (S00-T88) }\end{array}$ & Yes & 804143 (91.99) & 37309 (91.15) & $<0.001$ \\
\hline $\begin{array}{l}\text { External causes of } \\
\text { morbidity (V00- } \\
\text { Y99) }\end{array}$ & $\begin{array}{l}\text { No } \\
\text { Yes }\end{array}$ & $\begin{array}{r}813296(93.04) \\
60846(6.96) \\
\end{array}$ & $\begin{array}{r}37523(91.67) \\
3409(8.33) \\
\end{array}$ & $<0.001$ \\
\hline \multicolumn{5}{|c|}{ Other variables } \\
\hline $\begin{array}{l}\text { Number of body } \\
\text { systems operated } \\
\text { on }\end{array}$ & - & $0.05(0.23)$ & $0.07(0.27)$ & $<0.001$ \\
\hline $\begin{array}{l}\text { Number of } \\
\text { medications }\end{array}$ & $\begin{array}{l}{[0,5)} \\
{[5,10)} \\
10 \text { or more }\end{array}$ & $\begin{array}{r}818861(93.68) \\
53336(6.10) \\
1945(0.22) \\
\end{array}$ & $\begin{array}{r}37608(91.88) \\
3238(7.91) \\
86(0.21) \\
\end{array}$ & $<0.001$ \\
\hline $\begin{array}{l}\text { Season of ED } \\
\text { encounter }\end{array}$ & $\begin{array}{l}\text { Winter } \\
\text { Spring } \\
\text { Summer } \\
\text { Fall } \\
\end{array}$ & $\begin{array}{l}249118(28.50) \\
226456(25.91) \\
186163(21.30) \\
212405(24.30)\end{array}$ & $\begin{array}{r}10833(26.47) \\
10392(25.39) \\
9656(23.59) \\
10051(24.56) \\
\end{array}$ & $<0.001$ \\
\hline
\end{tabular}

\subsection{Results}

There were 144 EDs that met the inclusion criteria resulting in 1.1 million patients contributing 1.8 million ED encounters. Over $46.6 \%$ of the patients were less than 40 years and $22 \%$ were 60 or older. There were $62.7 \%$ female, 61.7\% Caucasians, and 23.6\% African American or Black; 43.0\% were on Medicare/Medicaid and $24.6 \%$ on Commercial Health Insurance. The top 5 respiratory conditions were acute upper respiratory infections $(32.39 \%)$, asthma $(25.26 \%)$, other chronic obstructive pulmonary disease $(15.19 \%)$, other diseases of upper respiratory tract (11.71\%), and unspecified bronchitis $(9.72 \%)$.

The summary statistics on the training dataset are shown in Table 3-1. The variable selection process resulted in 20 selected variables with $\mathrm{p}$ value less than 0.05 . Demographic and payer variables were all significant. Compared to patients with commercial insurance, patients with any 
other type of insurance (Medicare/Medicaid, self-pay, etc.) are more likely to have a return visit. Older patients tend to have a reduced risk compared to patients less than 40 years old. The race and ethnicity of the patient was associated with change in risk for return to the ED with 72 hours. Our results indicate that compared to Caucasians, African American/Black and Asian/Pacific Islander patients with respiratory conditions are less likely to return to the ED within 72 hours of discharge. Lastly, male patients are more likely to return than their female counterparts.

The health care utilization variables were strongly associated with changes in the risk for a return to the ED within 72 hours. Patients with one or more prior hospitalizations, if the index ED encounter is a revisit from a prior encounter, one or more prior ED visits, the maximum length of stay of prior ED visits, and history of previous return visits (excluding the index visit) were all risk factors of a return visit following the index ED encounter. It is interesting to note that our results indicate that a longer ED length of stay of the index visit is associated with increased odds of a subsequent visit.

The health care utilization variables were strongly associated with changes in the risk for a return to the ED within 72 hours. Patients with one or more prior hospitalizations, if the index ED encounter is a revisit from a prior encounter, one or more prior ED visits, the maximum length of stay of prior ED visits, and history of previous return visits (excluding the index visit) were all risk factors of a return visit following the index ED encounter. It is interesting to note that our results indicate that longer ED length of stay of the index visit is associated with reduced odds of a subsequent visit. This is in contrast with the length of stay of previous encounters being a risk factor with ED length of stay greater than 1 hour but less than 24 hours are less likely to have a return visit. 
Among the respiratory conditions, Intraoperative/postprocedural complications and disorders of the respiratory system (J95) was the only risk factor of a return visit within 72 hours after discharge. In other words, among patients with the respiratory condition or disease, intraoperative/postprocedural complication/disorders of the respiratory system are most at risk of a return visit. Certain respiratory conditions were associated with reduced odds of a return visit. These conditions include Acute upper respiratory infections (J00-J06), Other diseases of the upper respiratory tract (J30-J39), Pleural effusion, plague, and other pleural conditions (J90-J92, J94), Pulmonary disease affecting the interstitium (J81-J84), and Supprative necrotic conditions of the lower respiratory tract (J85-J86). Details on odds ratio and corresponding confidence intervals are shown in Table 3-2.

Table 3-2. Results

\begin{tabular}{|c|c|c|c|}
\hline \multicolumn{4}{|c|}{ Demographic Variables } \\
\hline Variables & Levels & Odds Ratio & $\mathbf{P}$ \\
\hline \multirow{5}{*}{ Payer } & Commercial & Reference & \multirow{5}{*}{$<0.01$} \\
\hline & Medicare/Medicaid & $1.18(1.16,1.21)$ & \\
\hline & Other governmental & $1.12(1.06,1.18)$ & \\
\hline & Self-pay & $1.13(1.10,1.16)$ & \\
\hline & Others & $1.13(1.09,1.17)$ & \\
\hline \multirow{3}{*}{ Age (Years) } & {$[18,40)$} & Reference & \multirow{3}{*}{$<0.01$} \\
\hline & {$[40,60)$} & $0.93(0.92,0.95)$ & \\
\hline & 60 or older & $0.93(0.91,0.95)$ & \\
\hline \multirow{3}{*}{ Race/Ethnicity } & Caucasian & Reference & \\
\hline & Hispanic & $0.97(0.91,1.04)$ & 0.42 \\
\hline & African American/Black & $0.92(0.90,0.94)$ & $<0.01$ \\
\hline
\end{tabular}




\begin{tabular}{|c|c|c|c|}
\hline & Asian/Pacific Islander & $0.91(0.83,1.01)$ & 0.07 \\
\hline & Native American & $1.05(0.98,1.13)$ & 0.14 \\
\hline & Others/Known & $0.94(0.90,0.97)$ & $<0.01$ \\
\hline \multirow{2}{*}{ Sex } & Female & Reference & \multirow{2}{*}{$<0.01$} \\
\hline & Male & $1.15(1.13,1.17)$ & \\
\hline \multirow{4}{*}{$\begin{array}{r}\text { Previous } \\
\text { hospitalization (prior } \\
6 \text { months) }\end{array}$} & 0 & Reference & \multirow{4}{*}{$<0.01$} \\
\hline & 1 & $1.20(1.17,1.24)$ & \\
\hline & 2 & $1.24(1.19,1.29)$ & \\
\hline & 3 or more & $1.38(1.32,1.45)$ & \\
\hline \multicolumn{4}{|c|}{ Healthcare Resource Utilization Variables } \\
\hline \multirow{3}{*}{$\begin{array}{r}\text { Length of stay, } \\
\text { hrs. }\end{array}$} & {$[0,1)$} & Reference & $<0.01$ \\
\hline & {$[1,24)$} & $1.09(0.93,1.29)$ & 0.28 \\
\hline & 24 or more & $1.10(0.88,1.36)$ & 0.41 \\
\hline \multirow{2}{*}{$\begin{array}{r}\text { Is index visit itself } \\
\text { a return visit? }\end{array}$} & No & Reference & $<0.01$ \\
\hline & Yes & $1.44(1.40,1.48)$ & \\
\hline \multirow{4}{*}{$\begin{array}{r}\text { Number of } \\
\text { previous ED visits } \\
\text { (prior six months) }\end{array}$} & 0 & Reference & $<0.01$ \\
\hline & 1 & $1.28(1.25,1.31)$ & \\
\hline & 2 & $1.48(1.44,1.53)$ & \\
\hline & 3 or more & $1.97(1.91,2.03)$ & \\
\hline $\begin{array}{r}\text { Longest length of } \\
\text { stay of previous ED } \\
\text { visits (prior six } \\
\text { months) }\end{array}$ & & $1.02(1.02,1.02)$ & $<0.01$ \\
\hline \multirow{6}{*}{$\begin{array}{r}\text { Number of } \\
\text { previous return visits } \\
\text { (prior 6 months) }\end{array}$} & 0 & Reference & \\
\hline & 1 & $1.32(1.28,1.36)$ & $<0.01$ \\
\hline & 2 & $1.90(1.81,1.99)$ & \\
\hline & 3 or more & $3.10(2.98,3.24)$ & \\
\hline & 0 & Reference & $<0.01$ \\
\hline & 1 & $1.28(1.25,1.31)$ & \\
\hline
\end{tabular}




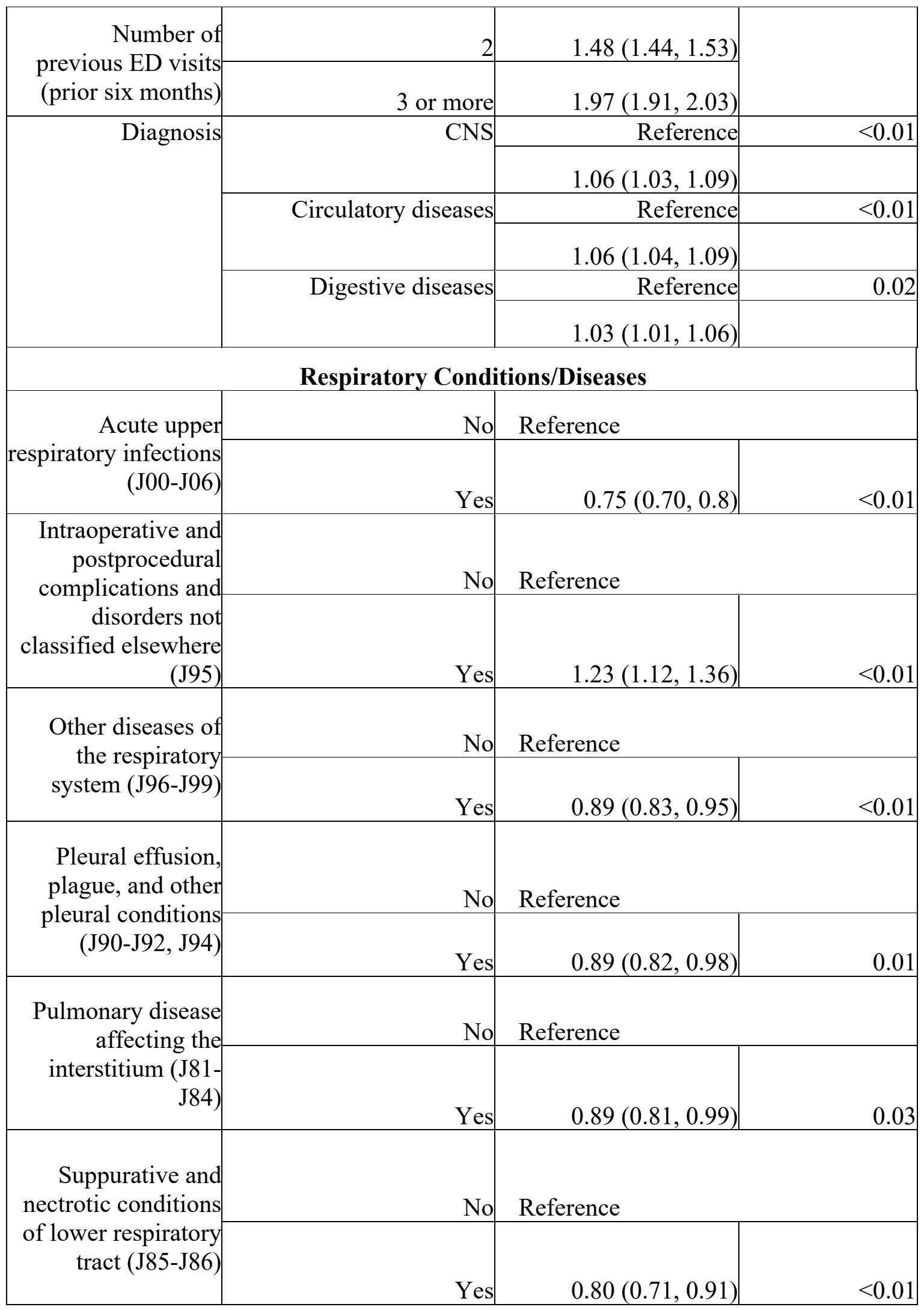


We calculated the ROC area under the curve for this model using the testing data set and received an AUC of 0.70. Based on previous work, the AUC in similar studies was between 0.60 and 0.65 , showing that our model performed very well. Figure 1-3 displays the AUC.

Figure 3-1. ROC curve with $\mathrm{AUC}=0.70$

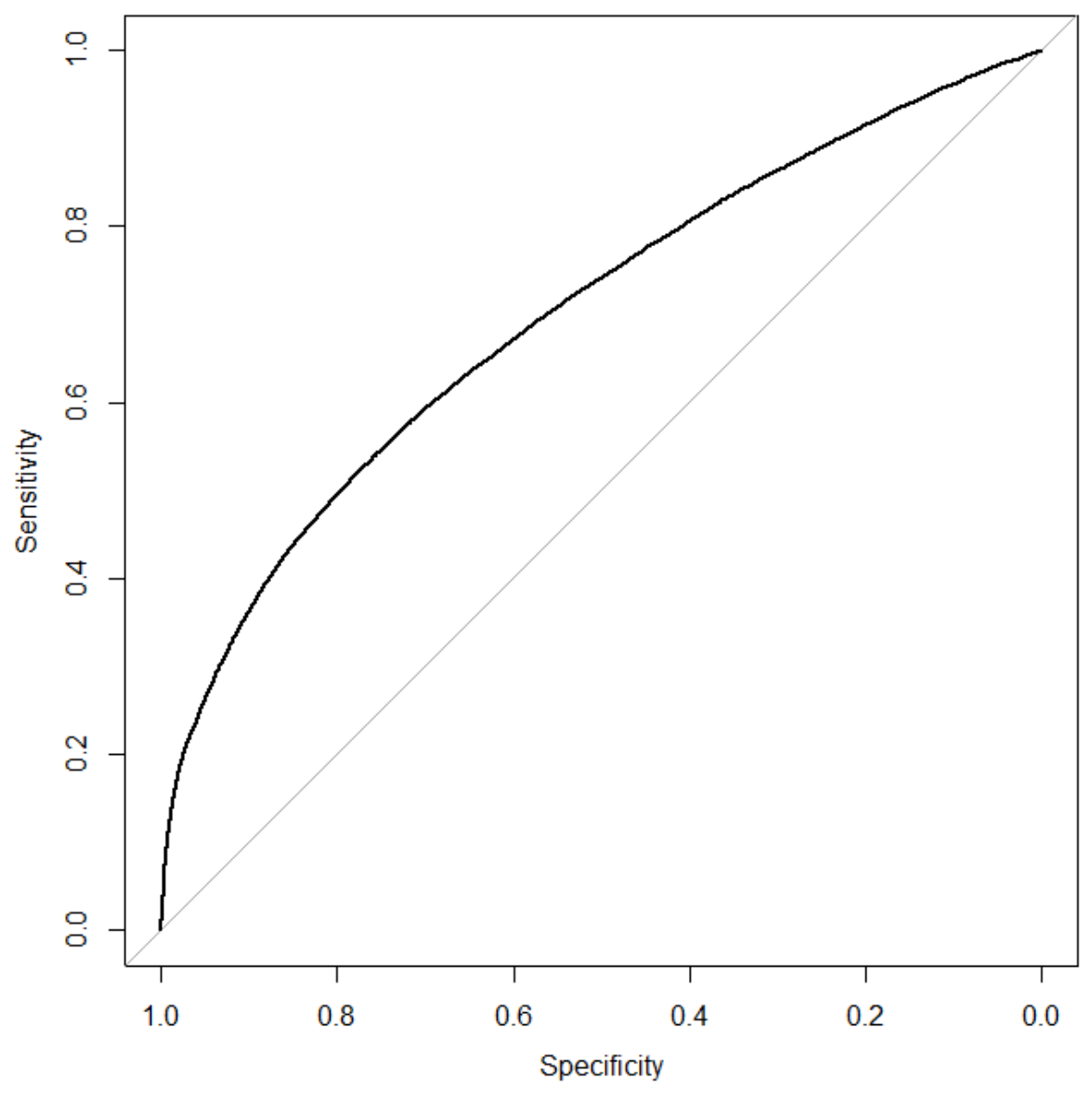




\subsection{Discussion}

The burden of respiratory diseases and conditions are further exacerbated by unnecessary or multiple trips to the emergency department. In over-crowded EDs, return visits may further burden the system and increase the time spent per patient in the treatment and resolution of patients' illnesses. Our results indicate that patients with respiratory conditions who are likely to return to the ED are often already high utilizers of the health care system. These are patients who have had previous hospitalizations and ED visits. These patients may therefore be burdened with difficult diagnoses or chronic comorbidities, experience a general degradation of health, or experience poor management of their health. This is further supported by the findings that the longer the time they spent during previous ED encounters, the more likely they are to return to the ED after the index encounter. Furthermore, a pattern of past and current return visits is highly predictive of future return visits or deterioration in health. Patients with history of return visits to the ED are at increased risk of future deterioration or encounter with the ED. This risk is more than double if there has been 3 or more such ED return visits within the prior 6 months. In addition, a patient who returns to the ED within 72 hours is more likely to repeat the trend, although it is not clear if this is attributable to poor management of their care or poor education on the use of the ED.

It is interesting to note that the medical/health insurance payer of the patient is a strong predictor of at-risk patients. This may be a proxy association with the social economic status of the patient. Our findings indicate that patients on Commercial insurance are less likely to return to the ED within 72 hours. We would expect the reverse to be the case but patients on Medicare/Medicaid or other lower income or governmental insurance are indeed more likely to return to the ED. We however suspect an interaction with the race and ethnicity of the patients. Our results indicate that Caucasian patients were more likely to return to the ED than patients of other races or ethnicity. 
The patient's sex was associated with differences in at-risk patients. Our model indicates that male patients tend to return to the ED within 72 hours more often than their female counterpart. There is no clear rationality for why this holds, which requires further studies. Another interesting finding is on the age of the patients. Younger patients are more likely to return to the ED than older patients. This may be confounded by the tendency to hospitalize older and frailer patients.

In terms of respiratory conditions that inflate the risk of a return visit, we found that patients with intraoperative and postprocedural complications and disorders of the respiratory system are most at risk of a return visit. This indicates that patients that present with these diseases and conditions to the emergency room require improved quality of care or education about the conditions they suffer from. These patients may provide a rich opportunity for improvements in the quality of care delivery, and for reduction in the return visits rate. In addition to these respiratory conditions, we discovered that comorbidities relating to the central nervous and circulatory systems further elevate the risk of readmission among these patients.

There are several limitations of this study. We relied exclusively on the use of diagnosis codes which may have administrative coding errors. The cohort of patients in this study was based on patients discharged home from the ED. This implies that we miss patients admitted to the hospital through the ED and return to the ED after discharge from the hospital. This limitation, however, is one of design and related to the question being asked. In our case, we are concerned in elucidating the difference between patients who return to the ED and those who do not among patients discharged home (and deemed not requiring hospitalization). In this multicenter study, we assessed the risk factors of return visits to the ED within 72 hours of previous discharge and evaluated the model performance. High rates of return visits to the ED may be associated with 
poorer outcomes and a marker for poor quality of care. As a result, these findings further improve on our ability to identify the most-at-risk patients with respiratory conditions. 


\section{REFERENCES}

1. Sparks, L., Cancer communication and aging [Special Issue]. Health Communication, 2003. 15(2).

2. Sparks, L., An introduction to cancer communication and aging: theoretical and research insights. Health Commun, 2003. 15(2): p. 123-31.

3. Sparks, L., Health communication and caregiving research, policy, and practice. Caregiving across the professions: A multi-disciplinary, coordinated perspective 2013: Springer. 131-175.

4. Sparks, L., \& Leahy, A. Conversing with Cancer: How to ask questions, Find and Share Information, and Make the Best Decisions. 2018; Available from: www.ConversingWithCancer.com.

5. Czaia, R., Manifredi, C., \& Price, J, The determinants and consequences of information seeking among cancer patients. J Health Commun, 2003. 8(6): p. 529-562.

6. Echlin, K.N. and C.E. Rees, Information needs and information-seeking behaviors of men with prostate cancer and their partners: A review of the literature. Cancer Nursing, 2002. 25(1): p. 35-41.

7. Leydon GM1, B.M., Moynihan C, Jones A, Mossman J, Boudioni M, McPherson K. , Cancer patients' information needs and information seeking behaviour: in depth interview study. BMJ, 2000. 320(7239): p. 909-913.

8. Pecchioni, L.L. and L. Sparks, Health information sources of individuals with cancer and their family members. Health Communication, 2007. 21(2): p. 143-151. 
9. Robinson, J.T., J., Impersonal, interpersonal, and hyper-personal social: Cancer and older adults. Health Communication, 2003. 15: p. 227-234.

10. Turk-Charles S, M.B., Gatz M, Age differences in information-seeking among cancer patients. Int Aging \& Human Devel., 1997. 45(2): p. 85-89.

11. Rakovski, C., Sparks, L., Robinson, J. D., Kee, K., Bevan, J., \& Agne, R., A regression-based study using jackknife replicates of HINTS III data: Predictors of the efficacy of health information seeking. Journal of Communication in Healthcare, 2012. 5(3): p. 163-170.

12. Waldie, M., \& Smylie, J., The Merck Lectureship: Communication: The key to improving the prostate cancer patient experience. Canadian Oncology Nursing Journal, 2012. 22(2): p. 129-133.

13. Moldovan-Johnson, M., Martinez, L., Lewis, N., Freres, D., \& Hornik, R. C., The Role of Patient-Clinician Information Engagement and Information Seeking from Nonmedical Channels in Fruit and Vegetable Intake Among Cancer Patients. Journal of Health Communication, 2014. 19(2): p. 1359-1376.

14. Kreps, G.L., \& Sparks, L, in The Encyclopedia of Cancer and Society

G.A. Colditz, Editor. 2015, The National Cancer Institute: Newbury Park, CA. p. 798-803.

15. Cantor, D., et al., Health information national trends survey (HINTS) 2007. Rockville, MD: Westat, 2009.

16. Shao, J., Bootstrap model selection. Journal of the American Statistical Association, 1996. 91(434): p. 655-665.

17. Wu, C.-F.J., Jackknife, bootstrap and other resampling methods in regression analysis. the Annals of Statistics, 1986. 14(4): p. 1261-1295. 
18. Lumley, T. and A. Scott, Fitting regression models to survey data. Statistical Science, 2017. 32(2): p. 265-278.

19. Min, Y. and A. Agresti, Modeling nonnegative data with clumping at zero: a survey. Journal of the Iranian Statistical Society, 2002. 1(1): p. 7-33.

20. Moloney FJ, A.E., O’Kelly P, Conlon P, Murphy GM. , Sunscreen Use Before and After Transplantation and Assessment of Risk Factors Associated With Skin Cancer Development in Renal Transplant Recipients. Arch Dermatol, 2005. 141(8)(978-982).

21. Wright, M.W., S.T. Wright, and R.F. Wagner, Mechanisms of sunscreen failure. J Am Acad Dermatol, 2001. 44(5): p. 781-4.

22. Haegen, G.E.V., The Effects of Adipose Fin Clipping and Coded Wire Tagging on the Survival and Growth of Spring Chinook Salmon. North American Journal of Fisheries Management, 2005: p. 1161-1170.

23. Von Bertalanffy, L., A quantitative theory of organic growth (inquiries on growth laws. II). Human biology, 1938. 10(2): p. 181-213.

24. Weibull, W., A statistical distribution function of wide applicability. Journal of applied mechanics, 1951. 18(3): p. 293-297.

25. Richards, F.J., A Flexible Growth Function for Empirical Use. Journal of Experimental Botany, 1959. 10(29): p. 290-300.

26. I. Mytilianios, M.S., H.K. Schofield, R.J.W. Lambert, Growth curve prediction from optical density data. International Journal of Food Microbiology, 2012. 154(3): p. 169176.

27. Sariyel, V., A. Aygun, and I. Keskin, Comparison of growth curve models in partridge. Poult Sci, 2017. 96(6): p. 1635-1640. 
28. Kideys, A.E., Determination of age and growth of Buccinum undatum L. (Gastropoda) off Douglas, Isle of Man. 1996. 50: p. 353-368.

29. Wright, W.G., The behavioral ecology of the limpet Lottia gigantea: interaction between territoriality, demography, and protandric hermaphroditism. 1985.

30. Nunes, C., A.M. Pereira, and M. Morais-Almeida, Asthma costs and social impact. Asthma Res Pract, 2017. 3: p. 1.

31. Kim, K.H., E. Kabir, and S. Kabir, A review on the human health impact of airborne particulate matter. Environ Int, 2015. 74: p. 136-43.

32. Rose, S., et al., Stigma-related experiences in non-communicable respiratory diseases: A systematic review. Chron Respir Dis, 2017. 14(3): p. 199-216.

33. Chamberlain SAF, G.R., Douiri A, et al., The impact of chronic cough: a crosssectional European survey. Lung, 2015. 193(3): p. 401-408.

34. Harrison, A., J. Montgomery, and F.B. Macgregor, Economic impact of recurrent respiratory papillomas in a UK adult population. J Laryngol Otol, 2016. 130(7): p. $645-9$.

35. Dalal, A.A., et al., Costs of COPD exacerbations in the emergency department and inpatient setting. Respiratory Medicine, 2011. 105(3): p. 454-460.

36. Pauwels, R.A. and K.F. Rabe, Burden and clinical features of chronic obstructive pulmonary disease (COPD). Lancet, 2004. 364(9434): p. 613-620.

37. Mannino, D.M. and A.S. Buist, Global burden of COPD: risk factors, prevalence, and future trends. Lancet, 2007. 370(9589): p. 765-773. 
38. Krall JR, M.J., Russell AG, Associations between source-specific fine particulate matter and emergency department visits for respiratory disease in four US cities. Environ Health Perspect, 2016. 125(1): p. 97-103.

39. Alman, B.L., et al., The association of wildfire smoke with respiratory and cardiovascular emergency department visits in Colorado in 2012: a case crossover study. Environ Health, 2016. 15(1): p. 64.

40. Song, X., et al., The impact of heat waves and cold spells on respiratory emergency department visits in Beijing, China. Sci Total Environ, 2018. 615: p. 1499-1505.

41. Sarnat, S.E., et al., Fine particulate matter components and emergency department visits for cardiovascular and respiratory diseases in the St. Louis, Missouri-Illinois, metropolitan area. Environ Health Perspect, 2015. 123(5): p. 437-44.

42. Malig, B.J., et al., A Time-Stratified Case-Crossover Study of Ambient Ozone Exposure and Emergency Department Visits for Specific Respiratory Diagnoses in California (2005-2008). Environ Health Perspect, 2016. 124(6): p. 745-53.

43. Ostro, B., et al., Associations of Source-Specific Fine Particulate Matter With Emergency Department Visits in California. Am J Epidemiol, 2016. 184(6): p. 450-9.

44. Xu, Q., et al., Fine Particulate Air Pollution and Hospital Emergency Room Visits for Respiratory Disease in Urban Areas in Beijing, China, in 2013. PLoS One, 2016. 11(4): p. e0153099.

45. Das LT, A.E., Stone AE, Kondrich JE, Kern LM, Grinspan ZM., Predicting frequent emergency department visits among children with asthma using EHR data. Pediatr Pulmonol, 2017. 52(7): p. 880-890. 
46. Abrams JY, W.R., Klein M, Associations between ambient fine particulate oxidative potential and cardiorespiratory emergency department visits. Environ Health Perspect, 2017. 125(10).

47. G., G.-G., The impact of indoor air pollution on the incidence of life threatening respiratory illnesses: evidence from young children in Peru. J Dev Stud, 2013. 49(4): p. $500-515$.

48. Ehteshami-Afshar, S., et al., The global economic burden of asthma and chronic obstructive pulmonary disease. Int J Tuberc Lung Dis, 2016. 20(1): p. 11-23.

49. Cukic, V., et al., Asthma and Chronic Obstructive Pulmonary Disease (COPD) Differences and Similarities. Mater Sociomed, 2012. 24(2): p. 100-5.

50. KS., R., Global Burden of Disease Study 2015 provides GPS for global health 2030. Lancet, 2016. 388(10053): p. 1448-1449.

51. Burney PGJ, P.J., Newson R, Minelli C, Naghavi M., Global and regional trends in COPD mortality, 1990--2010. Eur Respir J, 2015. 45(5): p. 1239-1247.

52. Kassebaum NJ, A.M., Barber RM Global, regional, and national disability-adjusted life-years (DALYs) for 315 diseases and injuries and healthy life expectancy (HALE), 1990--2015: a systematic analysis for the Global Burden of Disease Study 2015. . Lancet, 2016. 388(1053): p. 1603-1658.

53. Yeatts, K.B., et al., Population-based burden of COPD-related visits in the ED: return ED visits, hospital admissions, and comorbidity risks. Chest, 2013. 144(3): p. 784-793.

54. Martin-Gill, C. and R.C. Reiser, Risk factors for 72-hour admission to the ED. Am J Emerg Med, 2004. 22(6): p. 448-53. 
55. Lerman, B. and M.S. Kobernick, Return visits to the emergency department. J Emerg Med, 1987. 5(5): p. 359-62.

56. Calder, L., et al., Adverse events in patients with return emergency department visits. BMJ Qual Saf, 2015. 24(2): p. 142-8.

57. McCusker, J., et al., Hospital characteristics and emergency department care of older patients are associated with return visits. Acad Emerg Med, 2007. 14(5): p. 426-33.

58. Ehwerhemuepha, L., et al., A Novel Model for Enhanced Prediction and Understanding of Unplanned 30-Day Pediatric Readmission. Hosp Pediatr, 2018. 8(9): p. $578-587$.

59. Ehwerhemuepha, L., et al., A Statistical-Learning Model for Unplanned 7-Day Readmission in Pediatrics. Hosp Pediatr, 2020. 10(1): p. 43-51.

60. Kansagara D, E.H., Salanitro A, , Risk prediction models for hospital readmission: a systematic review. Jama, 2011. 306(15): p. 1688-1698.

61. Yohannes, A.M., The Impact of Comorbidities in Patients with Chronic Respiratory Diseases, in Depression and Anxiety in Patients with Chronic Respiratory Diseases. 2017, Springer. p. 129-148.

62. Heinze, G. and M. Schemper, A solution to the problem of separation in logistic regression. Stat Med, 2002. 21(16): p. 2409-19.

63. A., S. Apache Spark: Lightning-fast cluster computing. 2016; Available from: http//spark apache org.

64. Team., R.C. R: A Language and Environment for Statistical Computing. 2017; Available from: https://www.r-project.org/. 
65. Bates D, M.M., Bolker B, Walker S., Fitting Linear Mixed-Effects Models Using \{lme4\}. J Stat Softw, 2015. 67(1): p. 1-48. 


\section{APPENDICES}

\section{Table A-1}

Estimated Staying, Immigration, and Emigration rates for each period.

\begin{tabular}{|c|c|c|c|c|}
\hline Period & stayed & emigrated & immigrated & Density \\
\hline 1 & 0.596474359 & 0.403525641 & $\mathrm{NA}$ & $\mathrm{H}$ \\
\hline 2 & 0.59791908 & 0.40208092 & 0.371283784 & $\mathrm{H}$ \\
\hline 3 & 0.692520253 & 0.307479747 & 0.265626358 & $\mathrm{H}$ \\
\hline 4 & 0.48089182 & 0.51910818 & 0.418476025 & $\mathrm{H}$ \\
\hline 5 & 0.603396057 & 0.396603943 & 0.257978751 & $\mathrm{~L}$ \\
\hline 6 & 0.553314209 & 0.446685791 & 0.549270415 & $\mathrm{H}$ \\
\hline 7 & 0.467926635 & 0.532073365 & 0.340788334 & $\mathrm{~L}$ \\
\hline 8 & 0.648108788 & 0.351891212 & 0.602452575 & $\mathrm{H}$ \\
\hline 9 & 0.344184495 & 0.655815505 & 0.229783759 & $\mathrm{~L}$ \\
\hline 10 & 0.476072619 & 0.523927381 & 0.643769048 & $\mathrm{~L}$ \\
\hline 11 & 0.40857828 & 0.59142172 & 0.315003426 & $\mathrm{~L}$ \\
\hline 12 & 0.447833473 & 0.552166527 & 0.667880813 & $\mathrm{~L}$ \\
\hline 13 & 0.427098707 & 0.572901293 & 0.492850836 & $\mathrm{~L}$ \\
\hline 14 & 0.578408827 & 0.421591173 & 0.475675571 & $\mathrm{~L}$ \\
\hline 15 & 0.408917156 & 0.591082844 & 0.512710372 & $\mathrm{~L}$ \\
\hline 16 & 0.429697737 & 0.570302263 & 0.576582236 & $\mathrm{~L}$ \\
\hline 17 & 0.43964842 & 0.56035158 & 0.433762795 & $\mathrm{~L}$ \\
\hline 18 & 0.441516897 & 0.558483103 & 0.24125192 & $\mathrm{~L}$ \\
\hline 19 & 0.414880952 & 0.585119048 & 0.726259524 & $\mathrm{~L}$ \\
\hline 20 & 0.821719577 & 0.178280423 & 0.487801293 & $\mathrm{~L}$ \\
\hline 21 & 0.589910239 & 0.410089761 & 0.787350525 & $\mathrm{H}$ \\
\hline 22 & 0.705849176 & 0.294150824 & 0.297939526 & $\mathrm{H}$ \\
\hline 23 & 0.446710172 & 0.553289828 & 0.383261352 & $\mathrm{H}$ \\
\hline 24 & 0.528704137 & 0.471295863 & 0.265247203 & $\mathrm{~L}$ \\
\hline 25 & 0.565990842 & 0.434009158 & 0.627873627 & $\mathrm{H}$ \\
\hline 26 & 0.582796414 & 0.417203586 & 0.404220166 & $\mathrm{H}$ \\
\hline 27 & 0.447518267 & 0.552481733 & 0.238356008 & $\mathrm{~L}$ \\
\hline 28 & 0.456964803 & 0.543035197 & 0.632256729 & $\mathrm{~L}$ \\
\hline 29 & 0.444816942 & 0.555183058 & 0.471849725 & $\mathrm{~L}$ \\
\hline 30 & 0.363550784 & 0.636449216 & 0.488331958 & $\mathrm{~L}$ \\
\hline 31 & 0.423214286 & 0.576785714 & 0.484473068 & $\mathrm{~L}$ \\
\hline 32 & 0.482224959 & 0.517775041 & 0.643916256 & $\mathrm{~L}$ \\
\hline 33 & 0.497870164 & 0.502129836 & 0.453729538 & $\mathrm{~L}$ \\
\hline 34 & 0.480510753 & 0.519489247 & 0.486069508 & $\mathrm{~L}$ \\
\hline
\end{tabular}




\begin{tabular}{|r|r|r|r|l|}
\hline 35 & 0.473284871 & 0.526715129 & 0.472713865 & $\mathrm{~L}$ \\
\hline 36 & 0.47653603 & 0.52346397 & 0.526715129 & $\mathrm{~L}$ \\
\hline 37 & 0.3536678 & 0.6463322 & 0.358945579 & $\mathrm{~L}$ \\
\hline 38 & 0.434092827 & 0.565907173 & 0.623948162 & $\mathrm{~L}$ \\
\hline 39 & NA & NA & 0.571333333 & $\mathrm{~L}$ \\
\hline
\end{tabular}

